\title{
La doble vuelta en las elecciones presidenciales en Colombia 1994-2018 La búsqueda esquiva de mayor legitimidad y de consensos
}

\author{
The Double Round in the Presidential Elections in Colombia 1994-2018 \\ The Elusive Search for Greater Legitimacy and Consensus
}

Recibido: 12 de octubre de 2016 - Revisado: 9 de octubre de 2017 - Aceptado: 31 de julio de 2018

Javier Duque Daza²

\section{Resumen}

El artículo analiza la reforma que estableció la segunda vuelta en elecciones presidenciales en Colombia. Su objetivo es contrastar las previsiones de la teoría y sus concreciones en un estudio de caso: los cambios institucionales y su influencia en la competencia por la presidencia en el periodo 1994-2018. La idea central es que la reforma institucional ha contribuido al aumento del número de candidatos, a un mayor pluralismo y a la proyección de nuevos partidos; ha incentivado la formación de alianzas electorales y coaliciones de gobiernos y ha producido mayor legitimidad a los presidentes. El hallazgo principal es que, en este caso, se cumplen algunas de las previsiones teóricas, pero otras no.

\section{Palabras clave}

Elecciones, ballotage, sistema de partidos, legitimidad, coaliciones.
${ }^{1}$ El presente trabajo hace parte de la investigación "Relaciones entre poderes. El poder ejecutivo y sus relaciones con el Congreso en Colombia", financiado por la Universidad del Valle, convocatoria 2014-2015.

2 Politólogo. PhD Ciencia Política, Flacso México. Docente investigador Universidad del Valle.

Correo electrónico:

jduqued86@hotmail.com 0000-0001-9996-4835

Citación:

Duque-Daza, J. (2019). La Doble Vuelta en las Elecciones Presidenciales en Colombia 1994-2018. Civilizar: Ciencias Sociales y Humanas, 19(36), 77-102. doi: 10.22518/usergioa/jour/ccsh/2019.1/a05

\begin{abstract}
The article analyzed the reform that established the two-round system for Colombian presidential elections. The objective was to contrast the theory forecasts and their concretions in a case study: the institutional changes and their influence on the presidential races during the 1994-2018 period. The central argument is that institutional reform has contributed to an increase in the number of candidates, to greater pluralism and the projection of new parties. It also has encouraged the formation of electoral alliances and coalitions of governments and produced greater legitimacy for presidents. The main finding is that in this case, some of the theoretical forecasts were met, but others were not.
\end{abstract}

Keywords

Elections, election runoff, party system, legitimacy, coalitions. 


\section{Introducción}

Con situaciones diversas y a través de procedimientos diferentes, la mayoría de países de América Latina establecieron nuevas constituciones durante las últimas tres décadas. Los cambios afectaron, entre otros campos, al sistema electoral, el régimen de partidos y las relaciones entre los poderes públicos. Una constante ha sido la creación de nuevas reglas orientadas a generar una mayor inclusión y pluralismo político (Negreto, 2010). Los sistemas electorales incorporaron importantes modificaciones y en la mayoría de países fue establecido el sistema de doble vuelta presidencial o ballotage; solo cinco países mantienen el sistema de mayorías relativas a una vuelta: Honduras, México, Panamá, Paraguay y Venezuela. Con excepción de Bolivia, donde la segunda vuelta se realiza en el Congreso, en los otros países existe la segunda vuelta; en cuatro de ellos condicionada a un umbral: Argentina, Costa Rica, Nicaragua y Ecuador (Payne, Zovatto y Díaz, 2006).

Entre los académicos hay algunos acuerdos sobre los efectos esperados con la introducción del ballotage que se pueden sintetizar en cinco puntos: (1) la doble vuelta propicia mayor pluralismo al darle cabida a otras alternativas, a pequeños partidos, $\mathrm{y}$ a candidatos que entran en el juego de posibilidades; pueden proyectar sus nombres entre la opinión pública y sus agrupaciones políticas, así como impulsar programas y políticas; (2) la competencia tiende a moderarse y orienta las propuestas de los candidatos hacia el centro del espectro ideológico; (3) confiere mayor legitimidad al presidente de la república, el cual es elegido por una mayoría superior a la que genera la mayoría relativa, que puede resultar muy restrictiva, (4) facilita la estructuración de un sistema con múltiples partidos que tienden a agruparse en dos alternativas de disputa, (5) estimula la formación de coaliciones electorales y gobiernos con mayor apoyo parlamentario (Sartori, 1994; Martínez, 2006; Payne, Zovatto y Díaz, 2006; Crespo, 2008; Negretto, 2010).
No obstante los acuerdos, se han suscitado algunos debates respecto a posibles debilidades o aspectos contraproducentes de la segunda vuelta para la estabilidad política. Hay tres críticas que han encontrado respuestas de los defensores de esta regla (Katz, 2000; Martínez, 2006; Crespo, 2008): (1) El ballotage puede producir mayorías artificiales debido a la presencia del voto estratégico; aunque se contra-argumenta que el voto estratégico está potencialmente presente en todo tipo de sistema electoral, por lo cual no sería una consecuencia de la segunda vuelta, sino un comportamiento susceptible de asumirse siempre por parte del elector (Norris, 1997; Martínez, 2006). (2) La fragmentación del sistema de partidos puede producir polarización. Al respecto se señala que la polarización no necesariamente está asociada al sistema de partidos, pues hay bipartidismos también polarizados. Con la doble vuelta se tiende más a preservar el sistema de partidos existente. (3) Puede resultar inútil cuando el ganador de la segunda vuelta es el mismo de la primera. Sin embargo, se olvida que ese hecho expresa acuerdos entre partidos que representan a un mayor número de ciudadanos y por eso se trata de un ganador con mayor legitimidad.

Además de los anteriores argumentos a favor de la doble vuelta presidencial, hay otros cuatro aspectos más que podrían resultar contraproducentes para la estabilidad democrática. Por una parte, el tipo de alianzas. Se ha argumentado que las coaliciones tienden a ser electorales y no de gobierno, mientras que un sistema de mayoría relativa estimula alianzas más sustanciales que se convierten en coaliciones antes de las elecciones (Shugart y Carey, 1992, Shugart, 2007'; Molina, 2001; Chasquetti, 2001). De otra parte, la posible reversión del resultado de la primera vuelta aumenta la posibilidad de que se produzcan crisis de gobernabilidad, por cuanto un amplio sector de electores y dirigentes quedan en descontento al pasar de ganadores a perdedores (Pérez-Liñán, 2004 y 2006. En tercer lugar, y tal vez el asunto más complicado, el ganador final podría resultar derrotado en segunda vuelta por 
un candidato eliminado en la primera, si los votantes pudieran elegir de nuevo entre los dos. Esto implica que el resultado de este tipo de elecciones depende mucho de la coyuntura, de las circunstancias de la primera vuelta $\mathrm{y}$ del peso que puedan adquirir candidatos irrelevantes, si hay mucha fragmentación. El que triunfe no es necesariamente es el ganador (Buquet, 2002 Crespo, 2008). En cuarto lugar, fomenta el surgimiento de outsiders, políticos sin apoyos de partidos ni de congresistas, lo cual puede crear una dinámica centrada en los liderazgos más que en los partidos y produce una mayor volatilidad electoral (Katz, 2000; Crespo, 2008).

A la luz de estas consideraciones y de las previsiones planteadas, el artículo revisa el caso colombiano. La segunda vuelta fue establecida por la nueva Constitución Política de 1991, puesta en práctica desde 1994 y se ha aplicado en siete elecciones, aunque solo en cinco se ha requerido de ella. Se comparan los resultados de cinco elecciones presidenciales anteriores bajo mayoría relativa, desde 1974 cuando se reiniciaron las elecciones competitivas luego de finalizado el pacto de élites del Frente Nacio$\mathrm{nal}^{2}$, con las siete elecciones efectuadas bajo la vigencia del ballotage. El argumento central lo podemos desagregar en seis enunciados:

$\mathbf{E}_{1}$ : La conclusión de Michael Coppedge (2000), que asocia las mayores posibilidades de establecimiento de la doble vuelta a la preexistencia de un mayor número efectivo de partidos, encuentra en el caso colombiano una evidencia clara. La ruptura del bipartidismo en las elecciones de la Asamblea Nacional Constituyente en 1990 y la presencia de nuevos actores políticos relevantes abrió las puertas a reformas más incluyentes; dentro de estas, el establecimiento de la segunda vuelta en las elecciones presidenciales. Se presentó al momento de una coyuntura política.

$\mathbf{E}_{2}$ : La segunda vuelta ha contribuido al aumento del número de candidatos y a la pro- yección de nuevos partidos, en cuanto crea un escenario de mayor competencia y proyección de sus líderes, y de más espacios para las coaliciones. Tres indicadores nos permiten sustentar esta afirmación: el número de candidatos presidenciales, el número efectivo de candidatos ${ }^{3} \mathrm{y}$ el índice de concentración en los dos principales candidatos y partidos en la primera vuelta. ${ }^{4}$

$\mathbf{E}_{3}$ : No es claro que bajo el ballotage se genere siempre un significativo aumento del apoyo electoral al presidente electo y la consecuente mayor legitimidad. Los presidentes elegidos mediante segunda vuelta han logrado, como es lógico, mayor votación que en la primera vuelta; no obstante, en términos de votos efectivos (el porcentaje de votos obtenidos respecto al potencial electoral) no siempre han sido los presidentes elegidos mediante ballotage los de mayor respaldo.

$\mathbf{E}_{\mathbf{4}}$ : En cuatro de los cinco casos en los cuales se presentó doble vuelta, se estimuló la formación de coaliciones electorales y gobiernos con mayor potencial de apoyo parlamentario $(1998,2010,2014$ y 2018). Como contraparte, en 1994, la financiación con dinero del narcotráfico incidió en el triunfo en segunda vuelta de Ernesto Samper Pizano, bajo un formato bipartidista y sin terceras fuerzas con las cuales formar coalición, (1994-1998).

$\mathbf{E}_{5}$ : En dos elecciones se revirtió el resultado de la primera vuelta (1998 y 2014) y el ganador pasó a ser perdedor. En ausencia de una regulación del funcionamiento de los partidos y la permisibilidad para el transfuguismo, la segunda vuelta permitió que ganara el candidato del partido con minorías en el Congreso de la República.

$\mathbf{E}_{6}$ : En las elecciones presidenciales en Colombia no se han presentado más de tres candidatos relevantes con posibilidades reales de ganar, aunque ha habido candidaturas ficticias que toman las elecciones como una plataforma para obtener otro tipo de beneficios, o aspirar posteriormente a otros cargos. 
El artículo está dividido en tres partes. La primera, describe la implementación del $b a$ llotage en Colombia en una coyuntura crítica en el periodo 1990-1991 y sustenta el primer enunciado. La segunda, presenta un balance de los efectos sobre el sistema político: el mayor pluralismo y la presencia de outsiders; el apoyo electoral de los presidentes electos bajo los dos sistemas; el ballotage y la formación de coaliciones y los casos de reversión de resultados y desarrolla los enunciados 2 al 6. La tercera, esboza algunas conclusiones a la luz de los presupuestos teóricos propuestos y los resultados del análisis.

\section{La implementación del ballotage en Colombia en una coyuntura crítica}

Diversos estudios han enfatizado en la incidencia del sistema de partidos en los cambios institucionales. Michael Coppedge (2000) resaltó que cuanto más elevada es la fragmentación de una asamblea o cuerpo corporativo electo, mayor es la probabilidad de que se promueva una reforma electoral para adoptar el sistema de doble vuelta. Este argumento resalta el interés de los nuevos actores políticos en crear una segunda vuelta que les brinde posibilidades de competir, de establecer alianzas y coaliciones y les dé más protagonismo para futuras aspiraciones. En la misma línea, Josep Colomer (2004) ha argumentado que la implementación de los sistemas electorales no es la que determina cambios en el sistema de partidos; históricamente, han sido los cambios previos en el sistema de partidos los que han provocado reformas legislativas del sistema electoral que acomodan las normas electorales al nuevo contexto partidista. Se trata de invertir el clásico argumento de Maurice Duverger (1964) respecto a la incidencia de los sistemas electorales en el sistema de partidos 5 .

Reconociendo el papel del sistema de partidos y los efectos de los cambios institucionales, Dieter Nohlen (1994 y 1998) ha señalado que existe una lógica de causalidad recíproca entre sistemas electorales y sistemas de partidos y recalca la necesidad de ubicar el contexto socio-político en el cual se presentan las reformas. Desde este enfoque neoinstitucionalista contextualizado, el abordaje del cambio institucional que estableció la doble vuelta presidencial en Colombia implica reconocer que las reformas se dieron en una coyuntura crítica en la que diversas fuerzas sociales se manifestaron y presionaron la convocatoria a una Asamblea Nacional Constituyente. Esta fue elegida y quedó conformada de una forma plural, lo que rompió el histórico predominio bipartidista Liberal y Conservador. Hubo mayor número de partidos en circunstancias socio-políticas especiales y esto resultó definitivo en los cambios instituidos.

En Colombia predominó un sistema bipartidista fragmentado hasta finales de la década de 1980. Los partidos Liberal y Conservador, altamente divididos, mantuvieron su control absoluto en todas las corporaciones públicas y en la Presidencia de la República. A su vez, las terceras fuerzas políticas fueron muy débiles y marginales en término electorales, nunca obtuvieron más del cinco por ciento de escaños y votos. Este alto predominio bipartidista generó una especie de congelamiento institucional y el sistema electoral se mantuvo sin cambios por cuanto los dos actores políticos relevantes no introdujeron reformas que pudieran afectar sus posiciones y su predominio en las esferas gubernamentales y en los espacios de decisión. Solo una circunstancia excepcional podía producir un cambio institucional que modificara una parte de las reglas electorales vigentes y generara mayor inclusión y más pluralismo político ${ }^{6}$.

La circunstancia excepcional se presentó en la coyuntura 1990-1991. En la década de 1980 hubo una escalada de la violencia producto de la debilidad del Estado y su captura parcial por organizaciones criminales, y la presencia de diversos actores armados ilegales que el Estado era incapaz de contener y derrotar: guerrillas 
(las cuatro principales eran las Fuerzas Armas Revolucionarias de Colombia, FARC; El Ejército de Liberación Nacional, ELN; el Ejército Popular de Liberación, EPL; y el M-19. Las tres primeras surgidas a mediados de la década de 1960 y la cuarta en 1973); grupos paramilitares contra insurgentes vinculados con terratenientes y narcotraficantes (cuyos inicios se remontan a finales de la década de $1970^{7}$ ); carteles de la droga que retaban al Estado y cooptaban autoridades, funcionarios, militares y políticos (los dos principales los de Medellín y Cali, junto con otras organizaciones menores en varias ciudades y regiones del país). Producto de la acción de estos actores armados se dio un aumento gradual de la violencia con el incremento de los homicidios, de las acciones guerrilleras, de las masacres y del narcoterrorismo. El país estaba al borde del colapso y los medios internacionales se referían con frecuencia a Colombia como un caso de "Estado fallido" o "semi fallido".

En el periodo previo a las elecciones de 1990, la violencia llegó a extremos inéditos y fueron asesinados varios candidatos presidenciales: en octubre de 1987 fue asesinado Jaime Pardo Leal, ex candidato presidencial de la Unión Patriótica; el 18 de agosto de 1989, Luis Carlos Galán, candidato del Partido Liberal; el 22 de marzo de 1990, Bernardo Jaramillo Ossa, candidato de la Unión Patriótica y el 26 de abril de 1990, Carlos Pizarro, candidato del partido Alianza Democrática M-19. La tasa de homicidios del país era una de las más altas del mundo (70 por 100000 habitantes), el número de secuestros fue el más alto de la historia (2626), había millones de desplazados internos, decenas de masacres (58 en el año 1990), había tomas guerrilleras a diario, atentados con carrobombas y acciones terroristas (Acevedo, 2007; Codhes, 2009; Bello, 2008). El gobierno nacional, el Congreso y las demás instituciones políticas parecían impotentes e incapaces de gobernar al país; de contener el caos y la violencia. Un Estado precario, con muy baja gobernabilidad y estancado con instituciones que bloqueaban la democracia.
En este contexto socio-político se empezó a gestar la idea de una Asamblea Nacional Constituyente (ANC) que propiciara una salida a la crisis, reformara las instituciones $y$, de cierta forma, refundara al país. Se hablaba de un pacto de nuevo tipo. Convergieron análisis y propuestas de académicos; activismo social con movilizaciones de sindicatos, organizaciones sociales e indígenas; iniciativas políticas de los grupos insurgentes que se estaban desmovilizando (el M-19, la Corriente de Renovación Socialista, un reducto del EPL y el movimiento Quintín Lame). Por iniciativa de un movimiento estudiantil universitario gestionado desde Bogotá, se impulsó la idea de incluir en las elecciones de 1990 una séptima papeleta (además del voto para Cámara, Senado, alcaldes, concejales, diputados y Juntas Administradoras locales) para que los colombianos manifestaran si estaban a favor de convocar una Asamblea Nacional Constituyente; más del 85 por ciento votó por el sí. Tras el aval legal a la iniciativa por parte de la Corte Suprema, el gobierno de César Gaviria convocó las respectivas elecciones en diciembre de 1990 y la Asamblea inició labores en febrero de 1991 (Buenahora, 1991; Carrillo, 2001; Quintero, 2002).

Además de ser el producto de una coyuntura crítica, la ANC presentó cuatro características determinantes. Primero, se dio la oportunidad para una amplia participación ciudadana a través de las mesas de trabajo que funcionaron en todo el país y la población hizo llegar a los constituyentes sus propuestas de reforma. Segundo, ninguna de las fuerzas políticas logró obtener mayoría de sus escaños, por lo cual se impuso la lógica de las negociaciones incluyentes, de coaliciones y acuerdos para el establecimiento de la nueva carta política ${ }^{8}$. Tercero, los partidos históricos Liberal y Conservador se vieron enfrentados por primera vez en la historia del país a otras fuerzas políticas que lograron una importante representación. La ANC fue el primer escenario de elección popular sin predominio bipartidista, lo cual se expresó en el número efectivo de partidos que entre 1974 y 
1986 pasó de un promedio de 2,2 a 4,1 en estas elecciones ${ }^{9}$. A su vez, los sectores de izquierda que accedieron a la ANC asumieron una actitud más abierta, con mayor pragmatismo al abordar temas como la propiedad privada y la fuerza pública; sectores de derecha moderaron sus posiciones en temas de contenido social. La moderación de sectores políticos hizo posible la aproximación y acuerdos en muchos temas que antes eran intocables (Dugas, 1993). Cuarto, producto de sus propias dinámicas organizativas y el aprovechamiento de una coyuntura favorable en la cual hicieron el tránsito de organizaciones sociales a agrupaciones políticas con participación en las elecciones, hicieron presencia en la ANC actores indígenas y movimientos religiosos no católicos, que constituían minorías históricamente invisibles en lo político y solían ser excluidas de la toma de decisiones.

La ANC introdujo cambios importantes en el sistema electoral, aunque mantuvo las constantes históricas de este (el presidencialismo, el bicameralismo y la representación pro- porcional). Como el diagnóstico del cual partió la ANC indicaba que las restricciones del sistema político y el duopolio histórico del poder político había contribuido a la crisis que sufría el país y estimulado formas extra institucionales de oposición y participación política (entre ellas las guerrillas y las múltiples acciones colectivas y movimientos sociales contestatario), se consideró que los cambios debían aumentar la representatividad del sistema mediante la ampliación del número de partidos y de movimientos políticos con representación en el Congreso y en las corporaciones públicas municipales y departamentales (Pizarro, 2001). Así, se incluyeron las circunscripciones especiales para minorías afrodescendientes: un representante a la Cámara; la circunscripción única nacional para Senado, con dos senadores); la financiación estatal parcial de las campañas electorales y la flexibilidad en los requisitos para crear partidos, reducida a la consecución de firmas de respaldo; la elección popular de alcaldes y gobernadores, que venía desde 1988, aprobada en 1986; así como el cambio de reglas orientadas a debilitar

Tabla 1

Elección y conformación de la Asamblea Nacional Constituyente 1991

\begin{tabular}{|c|c|c|c|c|}
\hline \multirow[t]{2}{*}{ Partidos } & \multicolumn{2}{|c|}{ Votación } & \multicolumn{2}{|c|}{ Escaños } \\
\hline & Votos & $\%$ & Número & $\%$ \\
\hline Liberal & 1.158 .344 & 31,2 & 25 & 35,7 \\
\hline Alianza Democrática M-19 & 992.613 & 26,7 & 19 & 27,1 \\
\hline Movimiento de Salvación Nacional & 574.411 & 15,4 & 11 & 15,7 \\
\hline $\begin{array}{l}\text { Social Conservador }(5) \text { y conservadores } \\
\text { independientes }(4)\end{array}$ & 422.110 & 11,4 & 9 & 12,8 \\
\hline Unión Cristiana & 115.201 & 3,1 & 2 & 2,9 \\
\hline Unión Patriótica (izquierda) & 95.088 & 2,5 & 2 & 2,9 \\
\hline $\begin{array}{l}\text { Indígenas. Autoridades Indígenas de } \\
\text { Colombia (1) y ONIC (1) }\end{array}$ & 54.226 & 1,5 & 2 & 2,9 \\
\hline $\begin{array}{l}\text { Ejército Popular de Liberación (con voz } \\
\text { y voto). No elegidos. }\end{array}$ & ---- & ----- & 2 & 2,9 \\
\hline $\begin{array}{l}\text { Quintín Lame (con voz, sin voto). } \\
\text { Partido revolucionario de los } \\
\text { Trabajadores (voz, sin voto) }\end{array}$ & ----- & ----- & 2 & 2,9 \\
\hline Total & ----- & ----- & 74 & 100 \\
\hline
\end{tabular}

Nota: Fuente: elaboración propia con base en Registraduría Nacional del Estado Civil. 
el clientelismo político y contrarrestar la existencia de feudos electorales que reproducían el predominio inmutable y la sucesiva reelección de los dirigentes regionales ${ }^{10}$.

Respecto a la segunda vuelta en elecciones presidenciales, hubo consenso en la ANC. En su informe a la plenaria de la Asamblea, Carlos Lleras de la Fuente consignó que en los documentos de las comisiones preparatorias los diferentes proyectos presentados por el gobierno de César Gaviria, los voceros del Movimiento de Salvación Nacional, del Partido Liberal, de la Unión Patriótica, del movimiento Liberal-Movimiento Estudiantil, del Partido Conservador, de la Alianza Democrática M-19 y Autoridades Indígenas de Colombia estaban de acuerdo con este cambio. Solo un pequeño sector del Partido Conservador expresó su desacuerdo ${ }^{11}$.

En el informe de la Comisión Tercera a la Plenaria de la Asamblea, Lleras de la Fuente adoptó un argumento típico del institucionalismo y señaló que los sistemas electorales tenían una clara influencia tanto en los partidos como en la vida política, y recalcó:

Había una tendencia comprobada que los sistemas mayoritarios a una vuelta, que es nuestro sistema actual, implican un bipartidismo alternativo; los mayoritarios a dos vueltas un multipartidismo normalmente aliancista y que los sistemas de representación proporcional, aconsejables para las corporaciones públicas, suelen producir un multipartidismo independiente y ordenado. (ANC, 1991, p. 2).

El argumento apuntó a la conveniencia de mantener el sistema presidencial, la representación proporcional e introducir la doble vuelta presidencial. Era clara la intención de inclusión política para generar las condiciones de un mayor pluralismo. Así lo expresó el informe mencionado:

Sin entrar a analizar el bipartidismo, no podemos ignorar los cambios de nuestra actual vida política, debemos resaltar la aparición de nuevas fuerzas políticas, que constituyen realmente nuevas opciones de poder que deben tener garantizadas condiciones de participación política real, no solo en la conformación de las corporaciones públicas sino también en la integración del Gobierno. El sistema de doble vuelta, lo hemos dicho, estimula el multipartidismo y las terceras fuerzas, fortaleciendo la democracia y la diversidad de opciones, enriqueciendo así el devenir político de un pueblo. En consecuencia, se recomienda la adopción del sistema de mayoría absoluta o doble vuelta para elección de Presidente de la República. (ANC, 1991, p. 2).

En la Comisión Tercera se escucharon múltiples voces de los constituyentes de los distintos partidos a favor de la doble vuelta. Sectores minoritarios y de izquierda como la Unión Patriótica argumentaron a través de Alfredo Vázquez Carrizosa -un político conservador cercano a la izquierda- a favor de la propuesta porque generaba mayor pluralismo y podría romper el bipartidismo, pero debía ir acompañada del voto obligatorio y la prohibición de la reelección presidencial (ANC, 1991, p. 17). Uno de los constituyentes conservadores, Miguel Santamaría Dávila, recalcó el papel de la segunda vuelta en la generación de coaliciones, en la menor dispersión y en las posibilidades de mayores acuerdos de gobierno (ANC, 1991, p. 19). El constituyente liberal Guillermo Plazas Alcid estuvo de acuerdo con los argumentos anteriores y recalcó que la doble vuelta "oxigenaba la política partidista y hacía más responsable al ciudadano" (ANC, 1991, p. 20). Álvaro Echeverry Uruburo, de la Alianza Democrática M-19, defendió la doble vuelta porque "exige mayor respaldo ciudadano al Presidente, y estimula además el multipartidismo permitiendo a pequeños partidos tener juego en la democracia, apoyando a los grupos mayoritarios y obteniendo contraprestaciones políticas", pero se oponía a combinarla con la reelección, que iba en contravía del pluralismo (ANC, 1991, p. 13). Carlos Lleras de la Fuente, del Movimiento de Salvación Nacional, también fue defensor de la reforma de la doble vuelta. 
La inclusión del ballotage en la nueva Constitución Política fue asumida como otro componente en la búsqueda de mayor inclusión y mayor pluralismo político. En la exposición de motivos en la ANC, Hernando Yepes Arcila, delegatario del Partido Conservador, expresó como sigue acerca del propósito de la reforma:

Dentro del ánimo de fortalecer la democracia multipartidista es aconsejable mantener el sistema de representación proporcional para la elección de Congreso, asambleas y concejos; así como modificar el actual sistema de elección presidencial estableciendo la mayoría absoluta o doble vuelta, propiciando así el multipartidismo, la participación política de diversos sectores y un ambiente coalicionista en el Gobierno. Sin entrar a analizar el bipartidismo, no podemos ignorar los cambios de nuestra actual vida política. Debemos resaltar la aparición de nuevas fuerzas políticas, que constituyen realmente nuevas opciones de poder que deben tener garantizadas condiciones de participación política real, no sólo en la conformación de las corporaciones públicas sino también en la integración del Gobierno. El sistema de doble vuelta, lo hemos dicho, estimula el multipartidismo y las terceras fuerzas, fortaleciendo la democracia y la diversidad de opciones, enriqueciendo así el devenir político de un pueblo. En consecuencia se recomienda la adopción del sistema de mayoría absoluta o doble vuelta para la elección de Presidente de la República (Asamblea Nacional Constituyente, 1991, p. 2).

Así, tras un largo proceso de "congelamiento" institucional y de proyectos de reformas frustradas en décadas anteriores, en las nuevas condiciones y en un escenario en el cual debieron compartir el poder con otras agrupaciones políticas y una diversidad de sectores sociales, el bipartidismo cedió y el sistema electoral presentó cambios importantes. Respecto a las elecciones presidenciales se estableció la vicepresidencia por elección popular, se prohibió la reelección presidencial (que sería restablecida en 2004 y después prohibida de nuevo en 2015) y se estableció la segunda vuelta cuando ninguno de los candidatos obtuviera la mitad más uno de los votos. El texto aprobado con 10 votos a favor y dos abstenciones fue el siguiente:

La elección del Presidente de la República (y de miembros del Congreso) se hará (en un mismo día) en la forma que determine la ley; si en esta ocasión ningún candidato a la presidencia obtuviese la mayoría señalada en el inciso anterior, se celebrará una nueva votación de conformidad con la misma ley, (en fecha que señalará la organización electoral pero no antes de treinta días ni después de cuarenta y cinco días contados a partir de la fecha de la primera y en ella solo participarán los dos candidatos que en aquella hubiesen obtenido las dos más altas votaciones. Quien obtenga el mayor (ANC, 1991, p. 25).

\section{La Constitución quedó así:}

El Presidente de la República será elegido para un período de cuatro años, por la mitad más uno de los votos que, de manera secreta y directa, depositen los ciudadanos en la fecha $\mathrm{y}$ con las formalidades que determine la ley. Si ningún candidato obtiene dicha mayoría, se celebrará una nueva votación que tendrá lugar tres semanas más tarde, en la que sólo participarán los dos candidatos que hubieren obtenido las más altas votaciones. Será declarado Presidente quien obtenga el mayor número de votos. (Constitución política, 1991, art. 190).

En suma, este cambio institucional se aprobó a través de consensos, no de imposiciones, en una ANC multipartidista con nueva correlación de fuerzas y con la presencia y el aporte de nuevos partidos en una coyuntura crítica. Este cambio coadyuvó a las transformaciones en los siguientes lustros en el sistema de partidos, en el pluralismo, en la competencia y en la lógica de las alianzas electorales y las coaliciones de gobierno. 


\section{Balance de la aplicación de la doble vuelta}

Como se planteó en los enunciados de la introducción, el ballotage en Colombia ha tenido efectos esperados, pero también algunos que van en contravía de los presupuestos teóricos. En el balance se resaltan cuatro aspectos centrales: (1) el cambio institucional ha incentivado una mayor competencia y un mayor pluralismo político; (2) la doble vuelta ha estimulado las coaliciones y la conformación de gobiernos con mayor apoyo en el Congreso; (3) en dos casos se reversó el resultado, lo cual condujo a la creación de mayorías negativas en primera vuelta y los ganadores pasaron a ser perdedores; y (4) las elecciones con segunda vuelta no han representado siempre un mayor apoyo electoral a los presidentes electos, ni una mayor movilización en términos ponderados respecto al potencial electoral.

\section{Nuevos actores y más pluralismo.}

En Colombia, el espíritu de incorporación y de apertura política que orientó a la Asamblea Nacional Constituyente condujo a una serie de reglas que favorecieron la apertura del sistema político. Estas normas, combinadas con la poca regulación del funcionamiento de los partidos y la capacidad emergente de organización de diversos sectores sociales y políticos, llevaron a la multiplicación de las etiquetas partidistas y algunos de los nuevos partidos empezaron a postular candidatos en procura de mayor influencia nacional, difusión de sus propuestas y programas, y proyección de sus líderes. Esta apertura inicial fue muy inclusiva, pero llevó a la proliferación y la atomización del sistema de partidos, por lo que se establecieron nuevas reformas reductoras y racionalizadoras, sin limitar el pluralismo. La situación se modificó tras las reformas políticas del Acto legislativo 01 de 2003 y del Acto legislativo 01 de 2009. El abanico partidista empezó a cerrase de forma gradual y en el último ciclo electoral el efec- to reductor de las nuevas condiciones empezó a verse de forma más clara, con reglas como el umbral electoral, la prohibición de la doble militancia que limitó la presentación de disidencias bajo etiquetas diferentes y la introducción de la cifra repartidora en remplazo del sistema de cuotas y restos mayores (Duque Daza, 2011).

Después de siete elecciones, el balance muestra que hay mayor pluralismo y más alternativas políticas. Podemos apreciarlo a través de tres indicadores: (1) el número de candidatos y partidos en competencia; (2) su ponderación a través del número efectivo de candidatos en primera vuelta y; (3) el índice de concentración en los dos primeros partidos y candidatos en primera vuelta.

En cuanto al número de candidatos, se pasó de un promedio de 5,0 entre 1974-1986, a un promedio de 7,0 en el periodo 1994-2018 (Hubo 12 candidatos en la coyuntura de 1990, momento crítico de violencia cuando la Asamblea Nacional Constituyente fue convocada y empezaron a crearse nuevas organizaciones políticas). Desde 1994 se incrementó el número de candidatos y hubo 18 candidaturas. En las elecciones siguientes se redujo el número, pero siempre fue mayor al periodo anterior a la reforma -en 1998 fueron 13 candidatos, en 2002 hubo 11, luego en 2006 se presentaron 7, en 2010 fueron 9, en 2014 hubo 5 y en 2018 se presentaron 6- (ver Figura 1). En 2014 y 2018 se redujo de nuevo el número de candidatos, pero, a diferencia de lo que ocurrió en las décadas de 1970 y 1980, los partidos de los candidatos no eran marginales electoralmente, contaban con representación en el Congreso y todos los candidatos habían ocupado cargos dentro del Estado y/o tenían trayectorias políticas importantes. Es decir, se pasó de candidaturas marginales a otras con mayor capacidad de movilización electoral, con respaldo de organizaciones partidistas consolidadas y con mayor capacidad de coalición. Además del aumento en número, hubo un cambio cualitativo en las candidaturas. 
Si se toman solo aquellos candidatos que pertenecían a partidos con escaños en el Congreso (con lo cual podían aportar a una posible coalición de gobierno y a una eventual competencia) el promedio fue de 3,2 entre 1974 y 1990 y de 5,8 entre 1994 y 2018 . No se trata solo de candidatos testimoniales o de minorías que participaban con el fin de tener una tribuna para exponer sus ideas y programas. Hasta las elecciones de 1994, los candidatos Liberal y Conservador eran los únicos con expectativas reales de ganar pues contaban con recursos económicos propios y del Estado, el respaldo de los grandes gremios de la economía y las maquinarias de los políticos departamentales y municipales que los respaldaban con sus redes de electores. Eventualmente, hubo terceros candidatos de partidos de izquierda que participaban en las elecciones, pero sus votaciones eran marginales. Solo en la coyuntura de 1990 un tercer candidato logró movilizar más del diez por ciento de los votos ${ }^{12}$.

Desde 2002, todos los presidentes y los segundos lugares han sido de nuevos partidos: en 2006 ganó Álvaro Uribe Vélez (ex integrante del Partido Liberal y, en tal sentido, considerado un político tradicional) de Primero Colombia, con el respaldo de una amplia alianza multipartidista, y Carlos Gaviria, del Partido de izquierda Polo Democrático Alternativo, quien ocupó el segundo lugar y desplazó al Partido Liberal. En 2010 ganó el candidato Juan Manuel Santos (también ex integrante del Partido Liberal) del Partido Social de Unidad Nacional y el segundo lugar fue para el ex alcalde de Bogotá del Partido Alianza Verde, Antanas Mockus. En 2014 los dos primeros lugares fueron para Juan Manuel Santos, del Partido Social de Unidad Nacional y Óscar Iván Zuluaga, del nuevo partido Centro Democrático; un partido de muy reciente formación. En 2018 ganó las elecciones Iván Duque Márquez, del Centro Democrático y el segundo lugar fue para Gustavo Petro, candidato de izquierda, ex senador y quien fue candidato por el Movimiento Colombia Humana.

Esto último requiere una nota complementaria: en las cinco últimas elecciones la competencia ha incluido nuevas etiquetas partidistas, pero no todos los candidatos son nuevos líderes. Los nuevos partidos se han conformado, en mucho, por políticos que habían militado en los partidos tradicionales, sobre todo, en el Liberal, debido a dinámicas de desagregación y reagrupación. Así, nuevos y más partidos no implica nuevas figuras y liderazgos. Solo en las elecciones de 2018 ganó la presidencia un político joven, de nueva generación y sin antecedentes de militancia en el viejo bipartidismo.

También aumentó el número efectivo de candidatos. Se pasó de un promedio de 2,4 entre 1974 y 1990 a 3,2 entre 1994 y 2018. Desde 1994 no solo hay más candidatos de partidos con representación en el Congreso, también aumentó el número efectivo de actores en competencia; es decir, la competencia deja de estar centrada en dos candidatos y entran en juego otros partidos cuya votación es importante, lo que les confiere capacidad de coalición y relevancia en la definición de los resultados de la segunda vuelta.

Tabla 2

Indicadores de pluralismo en las Elecciones presidenciales 1974-2018

\begin{tabular}{|c|c|c|c|c|}
\hline Año & $\begin{array}{l}\text { Número } \\
\text { de can- } \\
\text { didatos } \\
\text { presiden- } \\
\text { ciales }\end{array}$ & $\begin{array}{l}\text { Número de } \\
\text { candidatos } \\
\text { presiden- } \\
\text { ciales de } \\
\text { partidos con } \\
\text { escaños en el } \\
\text { Congreso }\end{array}$ & $\begin{array}{l}\text { Número } \\
\text { efectivo de } \\
\text { candidatos }\end{array}$ & $\begin{array}{c}\text { Índice de } \\
\text { concentración } \\
(\%)\end{array}$ \\
\hline 1974 & 5 & 3 & 2,10 & 87,7 \\
\hline 1978 & 5 & 2 & 2,30 & 96,3 \\
\hline 1982 & 5 & 3 & 2,50 & $98,7^{*}$ \\
\hline 1986 & 5 & 3 & 2,11 & 94,1 \\
\hline 1990 & 12 & 5 & 3,03 & 87,0 \\
\hline 1994 & 18 & 4 & 2,45 & 90,3 \\
\hline 1998 & 13 & 6 & 3,21 & 68,9 \\
\hline 2002 & 11 & 6 & 2,47 & 86,4 \\
\hline 2006 & 7 & 5 & 2,21 & 84,3 \\
\hline 2010 & 10 & 8 & 3,48 & 68,0 \\
\hline 2014 & 5 & 5 & 4,79 & 55,0 \\
\hline 2018 & 7 & 6 & 3,10 & 64,4 \\
\hline \multicolumn{5}{|c|}{$\begin{array}{l}\text { Nota: * Incluye a los dos candidatos liberales, Alfonso López Michelsen } \\
\text { por el oficialismo y Luis Carlos Galán, por el Nuevo Liberalismo, así } \\
\text { como al candidato del Partido Conservador. Fuente: elaboración del } \\
\text { autor con base en estadísticas electorales de la Registraduría Nacional del } \\
\text { Estado Civil, años respectivos. }\end{array}$} \\
\hline
\end{tabular}


La mayor competencia y el mayor pluralismo de propuestas se expresa también en la disminución del índice de concentración y en la consecuente presencia de otros candidatos con altas votaciones. Hasta las elecciones de 1994 el bipartidismo concentraba más del 90 por ciento de los votos. En las elecciones siguientes disminuyó la concentración y el promedio entre 1998 y 2018 es de $71 \%$. Lo más significativo es que los partidos Liberal y Conservador fueron desplazados de la presidencia y dejaron de ser los principales protagonistas de la política en el país (ver Tabla 2).

El aumento de candidatos y el menor grado de concentración electoral en la última década se dieron en el marco del tránsito del bipartidismo, con partidos fragmentados, al multipartidismo. Cuatro factores incidieron: por una parte, la dinámica interna de los partidos Liberal y Conservador, cuyas divisiones se volvieron centrífugas. Muchos dirigentes políticos regionales y algunos líderes nacionales congregaron en torno a ellos círculos de apoyos políticos que conformaron las nuevas agrupaciones. Tras las elecciones presidenciales de 2002 en las que muchos congresistas liberales apoyaron al candidato disidente Álvaro Uribe Vélez y se incorporaron a la coalición de gobierno, hubo numerosas deserciones y surgieron nuevos partidos altamente personalizados bajo la dirección de congresistas que participaron de la distribución de los recursos por su posición en el nuevo gobierno (los principales fueron Cambio Radical y el Partido Social de Unidad Nacional, además de otros partidos que desaparecieron tras las investigaciones y condenas por sus nexos con grupos paramilitares, como Colombia Democrática, Apertura Liberal, Colombia Viva, Movimiento Nacional Progresista, Movimiento Popular Unido) ${ }^{13}$. Lo mismo sucedió con algunos movimientos internos conservadores que se autonomizaron y reagruparon a congresistas y políticos regionales (Equipo Colombia-Alas, el Unionismo, Conservatismo Independiente).
En segundo lugar, diversos sectores sociales y políticos lograron coordinar intereses y se organizaron dando origen a nuevos partidos. Los pequeños partidos de izquierda, que históricamente habían sido marginales, se unieron en un solo partido desde 2005 (el Polo Democrático Alternativo), lo cual hizo de la izquierda unida una fuerza política importante y con posibilidades de coalición (aunque desde 2012 empezó una nueva dinámica de división y deserción de algunos de sus principales dirigentes). Asimismo, se han mantenido en la competencia otras agrupaciones de tipo comunitario religioso (el Movimiento Independiente de Renovación Absoluta, que reúne a líderes y seguidores cristianos) y comunitario étnico (indígenas en diversos movimientos como Autoridades Indígenas de Colombia, Alianza Social Indígena, $\mathrm{y}$ algunos grupos de afrodescendientes). También se reagruparon algunos líderes políticos en el partido Alianza Verde, en el cual se refundó y redimensionó el anterior partido Opción Centro. En el Partido de Integración Nacional (PIN), luego rebautizado como Opción Ciudadana, se agruparon políticos regionales que procedían de partidos involucrados con organizaciones criminales paramilitares que desaparecieron, y otros liderazgos emergentes.

En tercer lugar, el tránsito hacia el multipartidismo se dio en un contexto de cambio institucional que creó incentivos y condiciones para la reconfiguración de los partidos. Con la reforma política de 2003 se prohibió la doble militancia, se estableció el umbral electoral del $2 \%$ de los votos para Senado (que desde el 2010 aumentó al 3\%), la mitad del cociente electoral para la Cámara de representantes y se instituyeron listas únicas, en reemplazo del sistema de avales sin límites existentes hasta 2002. Este último cambio fue complementado con el voto preferente como una de las opciones para las listas únicas, lo que incentiva las divisiones faccionales en torno a liderazgos regionales que manejan sus electorados propios, mantienen su relativa autonomía dentro de los partidos y estimula 
también el alto personalismo. De manera transitoria se estableció que los congresistas podrían agruparse y conformar nuevos partidos, siempre y cuando sus respectivas votaciones sumaran al menos el 2\% del total de votos válidos para Senado en las elecciones de 2002. Esta fue una ventana que utilizaron muchos congresistas para crear nuevos partidos, ante la necesidad de sobrevivir enfrentando los nuevos umbrales electorales. La mayoría de estos partidos fueron efímeros.

En cuarto lugar, algunas rupturas en las cúpulas político-partidistas derivaron también en nuevos partidos en el último lustro. Del Polo Democrático Alternativo se retiraron algunos dirigentes que se incorporaron y fortalecieron el partido Verde, rebautizado como Alianza Verde (como Antonio Navarro Wolf, Camilo Romero, Luis Eduardo Garzón, Antonio Sanguino), o que crearon una nueva agrupación como el denominado Progresismo dirigido por Gustavo Petro. Álvaro Uribe Vélez se separó de su núcleo de apoyo en el Partido Social de Unidad nacional y creó su propio partido, el Centro Democrático, al que se sumaron políticos de otros partidos (Partido Social de Unidad Nacional, Conservador, Equipo Colombia, Movimiento Popular Unido).
La transformación del sistema de partidos bajo nuevas reglas de juego ha permitido que nuevos liderazgos políticos se proyecten a través de las elecciones presidenciales con expectativas reales de éxito inmediato o con nuevas aspiraciones en otros cargos dentro del Estado. En 1998 fue Noemí Sanín, del movimiento Sí Colombia (después elegida embajadora en España e Inglaterra); en 2002 fue Luis Eduardo Garzón por el Frente Social y Político (elegido alcalde de Bogotá en 2003); en 2006 fue Carlos Gaviria por el Polo Democrático Alternativo (por primera vez la izquierda obtenía el segundo lugar). En 2010, fueron tres los candidatos que aspiraron a la presidencia: el ex alcalde de Bogotá, Antanas Mockus, (que después sería elegido senador en 2018), Germán Vargas Lleras (vicepresidente en las siguientes elecciones de 2014 y también candidato en 2018) y Gustavo Petro (elegido alcalde de Bogotá un año después). En 2014, con el respaldo de Álvaro Uribe Vélez, Oscar Iván Zuluaga obtuvo el primer lugar en la primera vuelta y perdió en la segunda ronda por una baja diferencia (el $2 \%$ de los votos). En 2018, Gustavo Petro compitió de nuevo (pasó a la segunda vuelta y perdió, pero accedió de nuevo a un escaño en el Senado como cabeza de la oposición y su fórmula vicepresidencial,

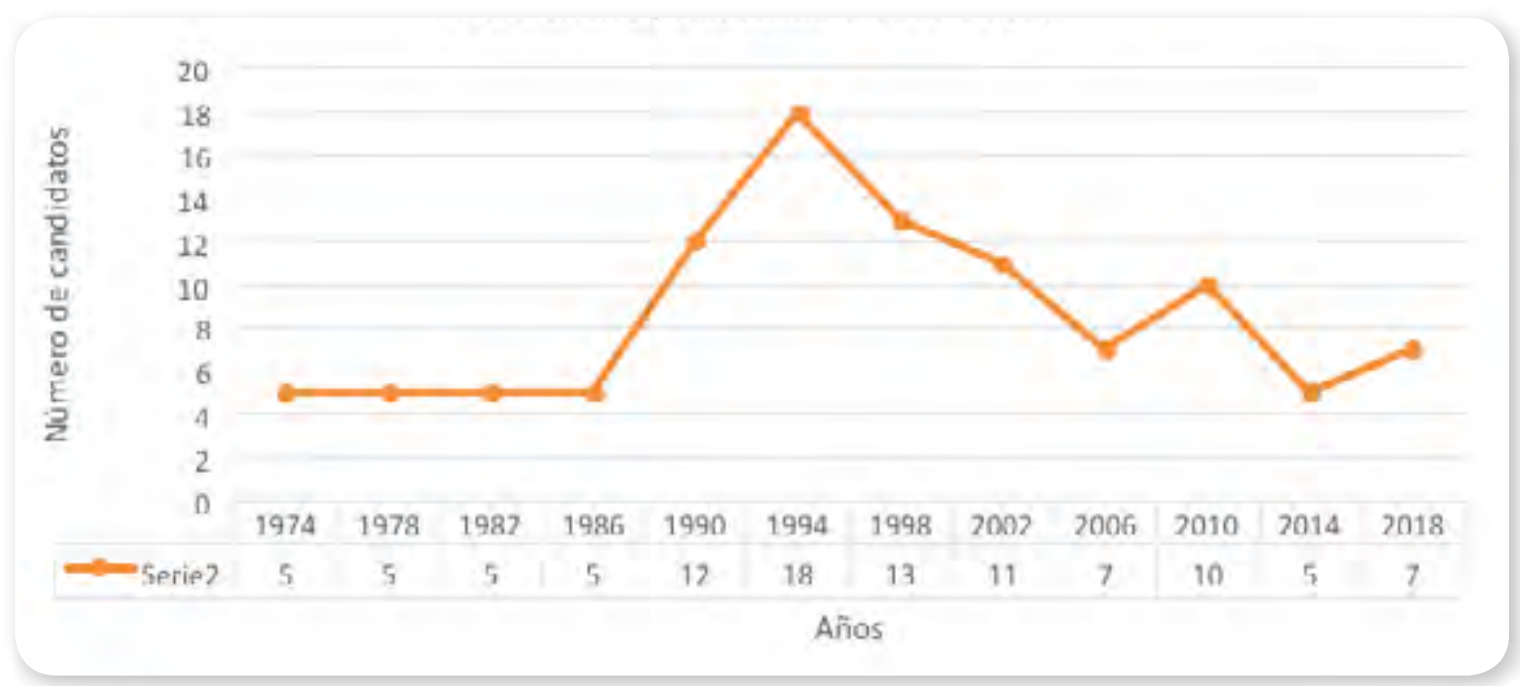

Figura 1. Colombia: evolución del número de candidatos en primera vuelta de las elecciones presidenciales, 1974 - 2018. Fuente: elaboración del autor con base en estadísticas electorales Registraduría Nacional del Estado Civil. 
Ángela María Robledo, obtuvo un escaño en la Cámara ${ }^{14}$ y Germán Vargas Lleras fue de nuevo candidato (relegado al cuarto lugar, pero mantiene su vigencia en la política nacional).

\section{Segunda vuelta y outsiders}

Con el establecimiento de la doble vuelta, políticos outsiders o liderazgos no partidistas procedentes de otras esferas de la sociedad y que incursionan en la política con relativo éxito también han competido por la presidencia. Una mayor dispersión de las preferencias en la primera vuelta y la consecuente redistribución del electorado, así como los segundos objetivos de algunos candidatos (mejor posicionamiento político, proyección de sus liderazgos, obtener mayor capacidad de negociación política y tomar la participación en la primera vuelta como una plataforma para las elecciones de la alcaldía de Bogotá) dieron pie para que en las elecciones se presentaran personas sin una importante tradición político-partidaria previa o que venían de afuera de la política electoral.

En las elecciones de 1994 se presentó Antonio Navarro Wolf, ex guerrillero del movimiento M-19 y ex constituyente que logró una mayor proyección nacional, aunque obtuvo una baja votación (el 3,8\% de los votos). Posteriormente sería Ministro de Salud, representante a la Cámara y Senador, alcalde de Pasto y gobernador de Nariño. En las elecciones de 2002 también fue candidato el ex sindicalista Luis Eduardo Garzón (ex presidente de la Central Única de Trabajadores y antes del Partido Comunista Colombiano), quien nunca había participado en una contienda electoral Obtuvo el $6,2 \%$ de los votos por el Frente Social y Político y ocupó el tercer lugar, lo cual le sirvió de plataforma para ganar en el siguiente año la alcaldía de Bogotá $^{15}$. Luego fue designado ministro de Trabajo (2014 - 2016). En las elecciones de 2006 obtuvo el segundo lugar el ex magistrado de la Corte Constitucional y profesor universitario Carlos Gaviria, del nuevo partido de izquierda Polo Democrático Alternativo, creado en 2005 (ocupó el segundo lugar con el $22 \%$ de los votos, superando al histórico Partido Liberal, aunque no hubo segunda vuelta). En las elecciones de 2010 pasó a la segunda vuelta Antanas Mockus, ex rector de la Universidad Nacional y ex alcalde de Bogotá por un nuevo movimiento político (fue el candidato por Alianza Verde, obtuvo el $21,5 \%$ de los votos en primera vuelta y $29,5 \%$ en la segunda) En 2018 Sergio Fajardo, profesor de matemáticas, ex alcalde de Medellín y ex gobernador de Antioquia por un movimiento independiente, ocupó el tercer lugar en la primera vuelta. Antes de establecerse el ballotage, este tipo de candidaturas eran poco frecuentes y las tercerías tenían un sentido testimonial y eran marginales electoralmente.

Aunque no es el caso de Colombia, el protagonismo de Outsiders en la competencia electoral puede conducir al triunfo de políticos sin apoyos de partidos ni congresistas y dar origen a gobiernos divididos con una fuerte oposición mayoritaria (Katz, 2000). Hipotéticamente, el paso a segunda vuelta en 1998 de Noemí Sanín pudo haber conducido a la presidencia a una candidata cuyo partido había elegido solo a tres congresistas, de un total de 265 , y si se hubiera concretado el triunfo de Antanas Mockus en segunda vuelta en 2010, hubiese tenido que gobernar con solo 8 de un total de 267 congresistas (el 3\%). En ningún caso existía una estructura partidista de respaldo, se trataba de movimientos circunstanciales creados expresamente para la campaña (1998) o al cual el candidato recién se vinculaba (2010). Asimismo, ante un eventual triunfo de Sergio Fajardo en 2018 (en el tercer lugar con el 23,8\%, con una mínima diferencia del 1,5\% del segundo lugar), no habría contado con un respaldo mayoritario en el Congreso.

La presencia de outsiders ha sido paralela al deterioro del histórico sistema bipartidista en el país y la negativa imagen de la mayoría de los partidos políticos. La percepción desfavorable de los partidos entre la población 
crea espacios para que surjan liderazgos que se presentan como anti partidistas o no partidistas, sin pasado ni cuestionamientos, sin compromisos con facciones y políticos clientelistas, que proyectan una imagen de personajes independiente, transparentes, no comprometidos con la corrupción y con nuevas propuestas. Con frecuencia recurren al eslogan "no más de lo mismo". Hasta 2018 no han logrado ganar las elecciones presidenciales, aunque sí han sido exitosos en algunas alcaldías y gobernaciones.

\section{¿Mayor legitimidad y apoyo?}

Contrario a lo que suele plantearse respecto al ballotage, las elecciones con segunda vuelta no siempre han generado mayor apoyo electoral en comparación con las del esquema de mayorías relativas y las diferencias entre los promedios de concurrencia entre unas y otras son poco relevantes.

Los presidentes elegidos mediante segunda vuelta han logrado, como es lógico, mayor votación que en la primera vuelta. Pero en tér- minos de votos efectivos (el porcentaje de votos obtenidos respecto al potencial electoral), no han sido los presidentes elegidos mediante segunda vuelta los de mayor apoyo. Estos presidentes han logrado mayor votación que en la primera vuelta, pero en votos efectivos, los mandatarios que mayor electorado movilizaron fueron elegidos en primera vuelta: Alfonso López Michelsen en 1974 (con el 32,7\% de los votos respecto al potencial electoral) y Álvaro Uribe Vélez en 2006 (con el 31,2\%). Asimismo, en promedio, las diferencias entre el apoyo recibido por los presidentes elegidos en primera vuelta $(25,5 \%)$ y los elegidos con ballotage $(26,7 \%)$ es mínima $(1,2 \%)$. Las segundas vueltas en Colombia no modifican las tendencias del bajo apoyo electoral de los presidentes respecto al potencial electoral (véanse Tabla 3 y Figura 2). La concurrencia electoral en este tipo de elecciones es muy baja y en el mejor de los casos, los presidentes solo son elegidos por menos de la tercera parte de los electores potenciales.

Como lo ha señalado Richard Katz (2000), en promedio las segundas vueltas proveen un

Tabla 3

Apoyo electoral de los presidentes electos respecto al potencial electoral

\begin{tabular}{|c|c|c|c|c|}
\hline Año & Presidente & $\begin{array}{l}\text { Potencial } \\
\text { electoral }\end{array}$ & $\begin{array}{l}\text { Votación del } \\
\text { Presidente }\end{array}$ & $\begin{array}{c}\text { Votación respecto } \\
\text { al potencial } \\
\text { electoral }\end{array}$ \\
\hline 1974 & Alfonso López Michelsen (P. Liberal) & 8.964 .472 & 2.929 .719 & 32,7 \\
\hline 1978 & Julio César Turbay Ayala (P. Liberal) & 12.580 .851 & 2.503 .681 & 19,9 \\
\hline 1982 & Belisario Betancur Cuartas (P. Conservador) & 13.734 .093 & 3.189 .278 & 23,2 \\
\hline 1986 & Virgilio Barco Vargas (P. Liberal) & 15.839 .754 & 4.214 .510 & 26,6 \\
\hline 1990 & César Gaviria Trujillo (P. Liberal) & 13.903 .324 & 2.891 .808 & 20,8 \\
\hline 1994 & Ernesto Samper Pizano (P. Liberal) & 17.147 .023 & 3.773 .366 & 22,0 \\
\hline 1998 & Andrés Pastrana Arango (P. Conservador) & 20.857 .801 & 6.086 .507 & 29,2 \\
\hline 2002 & Álvaro Uribe Vélez (Primero Colombia) & 24.208 .311 & 5.862 .655 & 24,2 \\
\hline 2006 & Álvaro Uribe Vélez (Primero Colombia) & 23.731 .700 & 7.397 .835 & 31,2 \\
\hline 2010 & Juan Manuel Santos (P. Social de Unidad Nacional) & 29.997 .574 & 9.004 .221 & 30,0 \\
\hline 2014 & Juan Manuel Santos (P. Social de Unidad Nacional) & 32.975 .158 & 7.839 .342 & 23,8 \\
\hline 2018 & Iván Duque Márquez (Centro Democrático) & 36.227 .267 & 10.398 .689 & 28,7 \\
\hline
\end{tabular}

Nota: *Resaltadas las elecciones con doble vuelta. Fuente: Elaboración propia con base en: Dieter Nohlen (1993), Enciclopedia electoral y del Caribe, Instituto Interamericano de Derechos Humanos, San José, para los datos entre 1974 y 1990 ; Registraduría Nacional del Estado Civil elecciones presidenciales para los años 1990-2014. 


\section{Gráfico 2: Colombia. Participación electoral elecciones presidenciales} respecto al potencial electoral

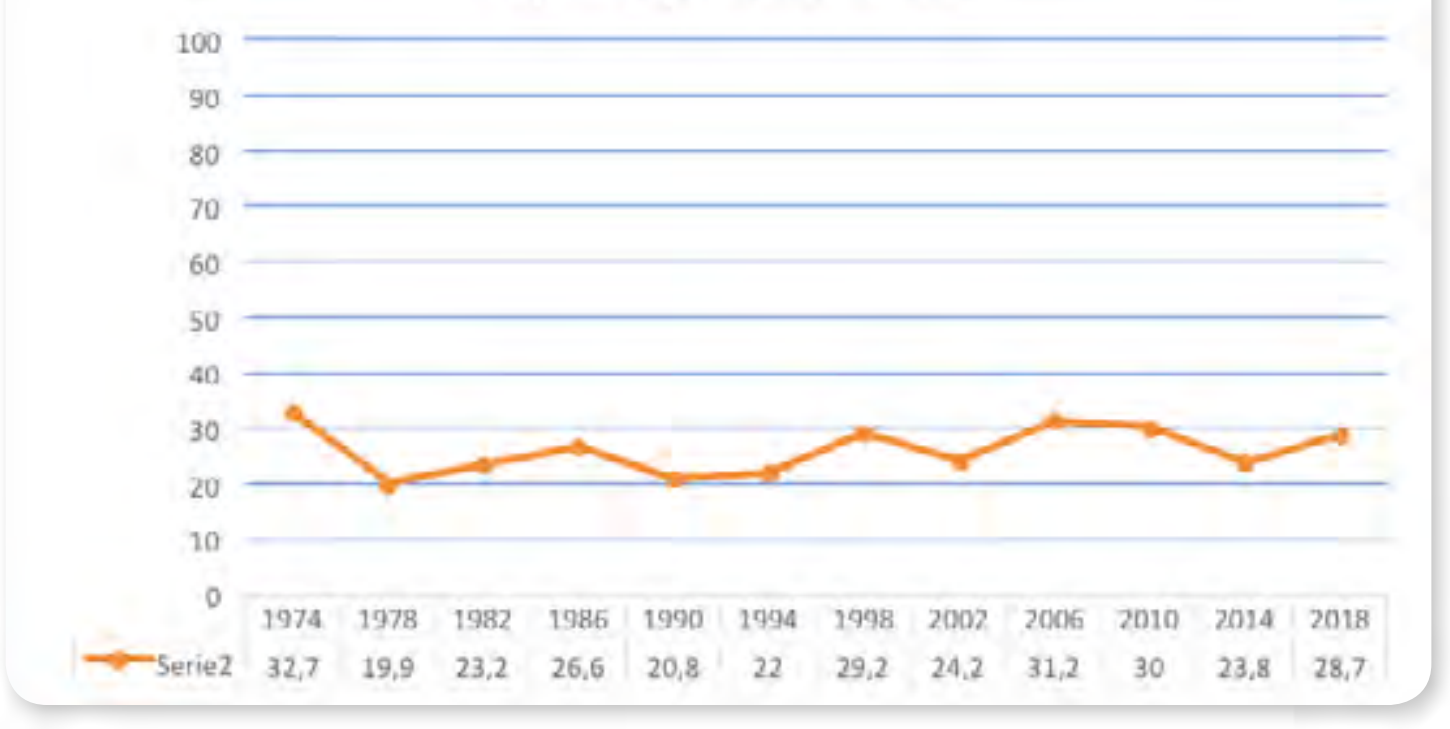

Figura 2. Colombia: Participación electoral elecciones presidenciales. Fuente: elaboración propia con base en datos de Registraduría Nacional del Estado Civil.

apoyo popular de los mandatos modestamente superiores a los de la primera vuelta. Además, hay que tener en cuenta que el apoyo que recibe es, en parte, proveniente de otro electorado que los respalda como segunda opción. La fortaleza del respaldo en las segundas vueltas es cuestionable, no solo porque en ocasiones expresa mayorías construidas con votos prestados, sino porque no logran movilizar apoyos mayoritarios del electorado habilitado para votar.

No siempre las elecciones con segunda vuelta conducen a una mayor movilización de electores, en términos absolutos. La votación total aumentó en cuatro de las cinco elecciones en que se ha llegado a doble vuelta, pero en 2010 disminuyó cerca del 10\%. En estas elecciones, la candidatura de Juan Manuel Santos congregó a todos los partidos que participaron en la primera vuelta y no pasaron a la segunda, mientras que el candidato Antanas Mockus se negó a hacer coaliciones, lo cual dejó por fuera al cuarto partido en votación, el Polo Democrático Alternativo, cuyo llamado a la abstención se reflejó en la disminución de la votación final. En 2014 aumentó la votación, pero no en la proporción esperada por la agrupación de los diferentes partidos en torno a los candidatos de la segunda vuelta. La votación aumentó sustancialmente en 2018, pero se produjo una situación inesperada: antiguos contradictores y opositores radicales se le unieron, como sucedió con los partidos Liberal, Cambio Radical y Partido Social de Unidad Nacional, además de la unión de tres ex presidentes, tradicionales contradictores y rivales, César Gaviria Trujillo, Andrés Pastrana y Álvaro Uribe Vélez (Ver Tabla 4).

Aunque las segundas vueltas no logren una significativa mayor movilización electoral respecto a los electores potenciales, no siempre aumente la votación en segunda vuelta, y se generen mayorías fabricadas mediante coaliciones heterogéneas y a veces paradójicas, el ballotage sí contribuye a prevenir situaciones potencialmente conflictivas, como la que habría sucedido en 1998. Ese año, en un momento de polarización política debido al escándalo de infiltración de los dineros del narcotráfico en la campaña de 
Tabla 4

Comparativo entre primera y segunda vuelta en elecciones presidenciales

\begin{tabular}{c|c|c|c|c} 
Año & Presidente electo & $\begin{array}{c}\text { Votación total en la } \\
\text { primera vuelta }\end{array}$ & $\begin{array}{c}\text { Votación total en la } \\
\text { segunda vuelta }\end{array}$ & Diferencia \\
\hline 1994 & Ernesto Samper Pizano & 5.726 .216 & 7.350 .147 & +1.623 .931 \\
\hline 1998 & Andrés Pastrana Arango & 10.507 .546 & 11.707 .226 & +1.199 .680 \\
\hline 2010 & Juan Manuel Santos & 14.515 .151 & 13.038 .370 & -1.476 .781 \\
\hline 2014 & Juan Manuel Santos & 13.209 .561 & 15.794 .940 & +2.583 .379 \\
\hline 2018 & Iván Duque Márquez & 7.618 .857 & 10.398 .689 & +2.779 .832
\end{tabular}

Nota: Fuente: elaboración propia con base en Registraduría Nacional del Estado Civil elecciones presidenciales años respectivos.

Ernesto Samper del Partido Liberal, el candidato de este mismo partido (Horacio Serpa Uribe) hubiese sido elegido en primera vuelta con algo más de la tercera parte de los votos $(34,5 \%)$ y el $15 \%$ de electores respecto al censo electoral; es decir, un precario apoyo y una débil legitimidad. En la segunda vuelta se revirtió el resultado y Andrés Pastrana Arango ganó las elecciones con el $51,3 \%$ de los votos y el $29,2 \%$ de los potenciales electores. La coalición y los acuerdos en la segunda vuelta impidieron que un candidato de un partido cuestionado por los nexos de muchos de sus congresistas, y del propio Presidente de la República, con el narcotráfico y con apoyo minoritario ganara las elecciones. Se previno la agudización de la crisis política.

\section{Elecciones presidenciales y coaliciones}

Como ya lo mencionamos, teóricamente el ballotage fomenta las coaliciones, a la vez que tiende a moderar las posiciones de los candidatos.

La lógica de las coaliciones se impuso por la transformación del sistema de partidos que transitó del bipartidismo con fragmentación interna a un multipartidismo moderado. Hasta las elecciones de 1994 se mantuvo un formato bipartidista y solo los candidatos liberales y conservadores tenían expectativas reales de éxito, a la vez que para el periodo 1974-1994 el número efectivo de partidos en el Congreso se mantuvo en promedio en 2,21 en Senado y en 2,18 en la
Cámara. Desde 1998 se fue abriendo el sistema, aumentó el número absoluto y relativo o efectivo de partidos, aunque con debilidades organizativas. Entre 1998 y 2018 el número efectivo de partidos legislativos para el Senado fue de 6,22 y en la Cámara de 5,54. Después de una alta fragmentación y la multiplicación de etiquetas partidistas entre 1991 y 2002 , las reformas políticas de 2003 y 2009 tuvieron un cierto efecto reductor con la disminución de partidos en competencia, pero con una distribución más pareja de sus curules y sus votos. Ningún partido por sí solo logra mayorías ni en el Congreso ni en las elecciones.

A la vez que otros partidos accedieron a escaños en el Congreso, a alcaldías y gobernaciones; avanzó el proceso de escisiones en los partidos Liberal y Conservador (surgió el Partido Social de Unidad Nacional y se consolidó Cambio Radical). Algunos congresistas se reagruparon y crearon nuevos partidos (como el Partido Verde, después rebautizado como Alianza Verde, Convergencia Ciudadana, después refundado como Partido de Integración Nacional y luego como Opción Ciudadana); la izquierda se unificó en el Polo Democrático Alternativo (que desde el 2010 se empezó a desagregar de nuevo) y en 2014 fue creado el Centro Democrático (fundado por el ex presidente Álvaro Uribe Vélez y su círculo de apoyos políticos y económicos). También surgieron nuevos liderazgos políticos que entraron a competir por la presidencia. Ante el desplazamiento de 
los lugares de preminencia de los partidos Liberal y Conservador, la mayor fragmentación del sistema y la presencia de nuevos competidores, en las elecciones presidenciales con segunda vuelta terminó por imponerse la lógica de las coaliciones desde 1998, al inicio fracciones y posteriormente, partidos. En el nuevo sistema ningún partido tiene la capacidad para alcanzar solo en primera vuelta la mayoría absoluta de votos. Se requiere de aliados y estos se asocian en la segunda vuelta.

Las elecciones de 1994 y 1998 fueron muy competitivas y polarizadas entre los partidos Liberal y Conservador. En 1994 las diferencias fueron mínimas, en las dos vueltas: un empate virtual en la primera (una diferencia del $0,3 \%$ ) y un cuasi-empate en la segunda (diferencia del 1,6\%). Los demás candidatos no tenían capacidad de negociación por sus bajos apoyos electorales, inferiores en su conjunto al 9\%. No había con quién hacer coaliciones, las posibilidades se limitaban a estrategias para atraer a sectores internos del otro partido o lograr una mayor movilización de los abstencionistas, o de electores independientes y de opinión. Tras las elecciones se presentó el escándalo de infiltración de los dineros del narcotráfico en la campaña presidencial de Ernesto Samper Pizano, quien obtuvo el triunfo, cuestionado por el candidato perdedor (Andrés Pastrana) y que después dio origen al escándalo y a que el mandatario fuera sometido a un proceso en la Cámara de representantes, que precluyó en 1996.

En 1998 se dio una dinámica de alianzas y divisiones internas que determinaron el resultado. En la primera vuelta hubo un empate técnico entre los candidatos Liberal (Horacio Serpa Uribe con el 34,6\%) y Conservador (Andrés Pastrana, 34,3\%), con una tercería que resultó de una alianza entre precandidatos de diversa procedencia ideológica y condujo a la candidatura de Noemí Sanín, de anterior militancia conservadora, pero candidata por el movimiento Sí Colombia (obtuvo el $26,5 \%$ de los votos). En estas elecciones se presentó una coa- lición del candidato conservador con un sector disidente del liberalismo desde la primera vuelta, lo cual afectó las mayorías del liberalismo que en las elecciones para Congreso había obtenido la mayoría absoluta de escaños y que se hubiera impuesto bajo elecciones con mayoría relativa. El escándalo de la filtración de dineros de la mafia del cartel de Cali en la campaña de Ernesto Samper de 1994 produjo una escisión dentro del Liberalismo que propició su derrota (esta estuvo comandada por el ex vicepresidente Humberto de la Calle, por Néstor Humberto Martínez y el ex fiscal Alfonso Valdivieso). Por su parte, la candidata de la tercería no hizo coalición y en una declaración pública manifestó que dejaba en libertad a sus electores para que decidieran por quien votar. En un ambiente político polarizado en la segunda vuelta se incrementó la votación (cerca de 1200000 votos) y ambos candidatos aumentaron sus electores de forma sustancial (Andrés Pastrana el 68,7\% y Horacio Serpa el 54,6\%). Estos se distribuyeron entre ambos candidatos, pero lo que determinó la elección fue el apoyo de un sector liberal al candidato Conservador.

Las elecciones de 2002 y 2006 las ganó el candidato disidente Liberal Álvaro Uribe Vélez en primera vuelta, quien logró agregar apoyos de políticos regionales de origen diverso, partidos de reciente creación y cuyos dirigentes resultaron involucrados en delitos por vínculos con grupos ilegales. En 2002, Uribe Vélez aglutinó al Partido Conservador y a los nuevos partidos Cambio Radical, Partido Social de Unidad Nacional, Equipo Colombia. Movimiento de Integración Regional, Movimiento Popular Unido, Convergencia Ciudadana, Convergencia Popular Cívica, Dejen Jugar al Moreno, Apertura Liberal, Alternativa de Avanzada Social, Movimiento Seriedad por Colombia, Participación Popular, Conservatismo Independiente, Movimiento Únete, además de congresistas liberales disidentes. En las elecciones de 2006, previa modificación de la Constitución por las mayorías del Gobierno que restableció la reelección presidencial pensando en su reelección, 
de nuevo ganó en primera vuelta y se mantuvo la coalición ganadora que obtuvo el $62,3 \%$ de votos y más del $70 \%$ de escaños en el Congreso. Se mantuvo el gobierno unificado a través de las mayorías fabricadas.

En las elecciones de 2010 se dio una mayor competencia en la primera vuelta dado que los partidos Cambio Radical y Conservador, que hacían parte de la coalición de gobierno, presentaron sus propios candidatos. La izquierda y el Partido Verde también compitieron. En la primera vuelta el ganador fue Juan Manuel Santos, del Partido Social de Unidad Nacional, quien alcanzó el $46,5 \%$ de los votos, con una ventaja de $20 \%$ sobre el segundo candidato (Antanas Mockus, del Partido Verde). En la segunda vuelta se formó una coalición ganadora con Cambio Radical (que había obtenido el $10,1 \%$ ), el Partido Conservador (que había obtenido el 6,1\%) y el Partido Liberal (que obtuvo el 4,4\%): el resultado fue un triunfo arrasador con el $69 \%$ de los votos. Solo no pudo ganar en primera vuelta, y en coalición le sobraron votos (y socios políticos) a su triunfo.

En estas elecciones hubo tres candidatos ficticios, que sabían que no podían ganar, pero con su participación entraban en el juego de las coaliciones, lograban un potencial mejor posicionamiento $\mathrm{y}$, eventualmente, podían acceder a una parte de los recursos del poder. Ese año se conformó una coalición de índole pragmática y por reparto en torno al candidato del Partido Social de Unidad Nacional. Los ex candidatos presidenciales ingresaron al gabinete como ministros después del triunfo (del Interior y Justicia Germán Vargas Lleras y de Trabajo, Rafael Pardo). Otros integrantes del Partido Conservador ocuparon altos cargos. Luego conformaron la coalición de gobierno bajo la denominación de Unidad Nacional. A esta se incorporó el Partido Verde, con cuyo candidato Antanas Mockus se había enfrentado en segunda vuelta.

Las elecciones de 2014 fueron también muy competitivas y hubo un juego de coalicio- nes en la disputa por la presidencia. En primera vuelta hubo cinco candidatos y ganó el nuevo partido creado por el ex presidente Álvaro Uribe Vélez, Centro Democrático, disidente del Partido Social de Unidad Nacional (el candidato fue Óscar Iván Zuluaga, que obtuvo el 29,3\%), Juan Manuel Santos ocupó el segundo lugar, por la alianza del Partido Social de Unidad Nacional y Cambio Radical (con el 25,7\%). Hubo otros tres candidatos: Marta Lucía Ramírez, del Partido Conservador (15,5\%); Clara López Obregón, del Polo Democrático Alternativo (15,2\% de votos) y Enrique Peñalosa, de Alianza Verde (8,3\% de votos). En la segunda vuelta, el Partido Conservador dividió su apoyo, el PDA y la Alianza Verde respaldaron a Santos, quien al fin se impuso por un estrecho margen (obtuvo el $51 \%$ ). Ningún candidato tenía la capacidad para ganar en primera vuelta y el juego de coaliciones determinó el resultado final. Se revirtió el resultado y el ganador contó con un sustancial mayor respaldo electoral que el que obtuvo el triunfador en primera vuelta.

En 2018 hubo de nuevo un amplio juego de coaliciones en dos etapas. Antes de la primera vuelta se unieron tres candidatos que hicieron una consulta interpartidista: Iván Duque Márquez, del Centro Democrático (elegido mediante un procedimiento interno en su partido), Alejandro Ordoñez y Marta Lucía Ramírez, que se habían inscrito mediante firmas, previa renuncia al Partido Conservador, del cual una parte de sus congresistas se le unieron. Se sumaron también organizaciones políticas cristianas con representación en el Congreso (Movimiento MIRA y Colombia Justa Libres). También se juntaron en la denominada Coalición Colombia los candidatos Sergio Fajardo, del Movimiento Compromiso Ciudadano, Claudia López, de Alianza Verde y Jorge Robledo, del PDA. En torno al candidato Germán Vargas Lleras se unieron los partidos Cambio Radical, Opción Ciudadana, un sector del Partido Social de Unidad Nacional, un sector del Partido Conservador. Gustavo Petro se presentó por el Movimiento Colombia Humana, con apoyo de la Unión Patriótica y el 
Partido Comunista, y Humberto de la Calle por el Partido Liberal, apoyado por Alianza Social Independiente. En la primera vuelta se impusieron Iván Duque Márquez y Gustavo Petro. En la segunda vuelta se sumaron a Duque los partidos derrotados Liberal, Cambio Radical y Social de Unidad Nacional. A Petro se sumaron sectores de la Alianza Verde y el PDA. Como ya se mencionó, se impuso Iván Duque, el candidato que más partidos agregó, sin que contara mucho la disparidad de posiciones y las anteriores confrontaciones entre sus principales líderes, agrupados a la derecha del espectro ideológico.

En síntesis, tras siete elecciones bajo el sistema majority run-off, desde 1998 se ha generado una dinámica de coaliciones entre sectores y entre partidos. En una elección no hubo coalición (1994), en otra la coalición se concretó entre un partido (Conservador) y sectores del otro (Liberal), en otras dos (2002 y 2006) se gestó una coalición "atrapa-todo" en la primera vuelta en torno al candidato Álvaro Uribe Vélez que congregó partidos de diversa procedencia (algunos de dudosa procedencia por su vínculos con organizaciones criminales), aunque con banderas neoconservadoras muy cercanas a la derecha ideológica. En otras dos elecciones (2010 y 2014) se dieron coaliciones en la segunda vuelta entre los partidos más próximos y en los comicios de 2018 la gran mayoría de partidos se agruparon para enfrentar a un candidato emergente de izquierda.

\section{Conclusión}

El establecimiento de la segunda vuelta presidencial en Colombia se concretó a través de un amplio consenso entre los partidos en la Asamblea Nacional Constituyente de 1991. Este cambio institucional se justificó argumentando que hacía posible el tránsito hacia un sistema multipartidismo, un mayor pluralismo, mayor participación política de diversos sectores y una dinámica de coaliciones en el Gobierno. Después de siete elecciones bajo la vigencia de esta ¿qué ha sucedido en el caso colombiano respecto a lo que prevé la teoría? ¿Cuáles han sido los efectos de esta reforma en las elecciones y en la dinámica partidista?

En cuanto a las previsiones señaladas por la teoría el caso colombiano permite verificar cuatro aspectos: (a) el aumento del número de partidos en la coyuntura crítica de 1989-1990 permitió que la propuesta de la doble vuelta se abriera paso y fuera aprobada; (b) ha propiciado un mayor pluralismo al darle cabida a otras alternativas, a pequeños partidos y a candidatos que entran en el juego con mayores posibilidades de ganar; (c) ha estimulado la formación de alianzas electorales y coaliciones de gobiernos con mayor apoyo parlamentario y gobiernos unificados a través de coaliciones; (d) nominalmente, la segunda vuelta ha conferido mayor legitimidad al presidente derivado del mayor respaldo electoral, a diferencia de la que genera la mayoría relativa, que puede resultar muy restrictiva y conducir a que haya presidentes elegidos por minorías y que cuentan con una robusta oposición que puede bloquearlo.

No obstante, hay resultados esperados que no se han dado: (a) se prevé que las propuestas se moderan y se orientan hacia el centro del espectro ideológico, pero en las elecciones desde el 2002 se ha incrementado la polarización política. En 2002 entre un candidato de derecha y su coalición (Álvaro Uribe Vélez) y el candidato del Partido Liberal (Horacio Serpa Uribe) y en el 2006 entre Álvaro Uribe y su coalición y el candidato de izquierda del Polo Democrático Alternativo, Carlos Gaviria; en los dos gobiernos de Juan Manuel Santos (2010-2018) se radicalizó la oposición de derecha comandada por Álvaro Uribe Vélez, desde el 2014 con el partido Centro Democrático; (b) no siempre la segunda vuelta ha producido una mayor movilización de electores $\mathrm{y}$, por ende, una mayor legitimidad. En las elecciones de 2010 hubo menos electores en la segunda vuelta que en la primera; y (c) aunque los presidentes electos en segunda vuelta cuentan con el respaldo de 
más electores, en términos ponderados respecto al potencial electoral, son mínimas las diferencias entre presidentes elegidos en primera y en vuelta.

Respecto a quienes plantean que la doble vuelta puede producir resultados contraproducentes para la estabilidad democrática, los resultados muestran que: (a) como ningún partido tiene la capacidad de ganar solo las elecciones, se han conformado coaliciones de gobierno, pero con un carácter transaccional y de reparto de incentivos, con muy poca coherencia ideológica (Duque Daza, 2008); (b) respecto a la reversión del resultado de la primera vuelta y la posibilidad de que se produzcan crisis de gobernabilidad por el descontento de quien pasa de ganador a perdedor, en Colombia se han dado dos casos: en 1998 Horacio Serpa Uribe, del Partido Liberal, ganó en primera vuelta y Andrés Pastrana Arango, del Partido Conservador triunfó en la segunda. El perdedor aceptó el resultado y no se dieron cuestionamientos ni se produjo crisis política. El segundo caso fue diferente. En el 2014 el ganador en primera vuelta fue Óscar Iván Zuluaga, del Centro Democrático, sobre Juan Manuel Santos, de la unión del Partido Social de Unidad Nacional y Cambio Radical; en la segunda vuelta se revirtió el resultado. El partido perdedor acusó de fraude al ganador y se produjo una fuerte polarización política y oposición desleal a todos los actos del gobierno; (c) la segunda vuelta fomenta el surgimiento de outsiders, políticos sin apoyos de partidos ni de congresistas, lo cual puede crear una dinámica centrada en los liderazgos más que en los partidos. Esto ha sucedido, pero no han tenido éxito en las elecciones.

Es claro que la doble vuelta genera mayores espacios para la competencia, propicia coaliciones, modera las posiciones de los candidatos, confiere mayor legitimidad y evita que haya ganadores minoritarios. No obstante, no es suficiente para movilizar más apoyos ciudadanos a los partidos. En términos relativos, todos los presidentes han sido elegidos con muy bajos porcentajes del potencial electoral. Una nueva regla de juego no soluciona problemas estructurales de los partidos y de la clase política ni hace que la desconfianza y apatía de la mayoría de los electores se modifique.

\section{Referencias}

Acero, H. (2007). Violencia homicida en Colombia 1960-2006. Liderazgo político y políticas públicas. Criminalidad 49, 124-133.

Asamblea Nacional Constituyente - ANC. (1991). Informe a la Comisión Tercera de la Asamblea Nacional Constituyente. Asunto: Elección del Presidente por el sistema de doble vuelta; periodo; calidades; posesión y no reelección. Bogotá, Colombia: Gaceta Constitucional. Recuperado de http://babel.banrepcultural.org

Bello, C. (2008). La violencia en Colombia: análisis histórico del homicidio en la segunda mitad del siglo XX. En Revista Criminalidad. Policía Nacional de Colombia. 50(1) 75-83.

Buenahora, J. (1991), El proceso constituyente: de la propuesta estudiantil a la quiebra del bipartidismo, Bogotá, Colombia: Tercer Mundo Editores.

Buquet, D. (2004). Balotaje vs. mayoría simple: el "experimento" uruguayo. En R. Martínez (Coord.), La elección presidencial mediante doble vuelta en Latinoamérica (pp. 483-499). Universitat Autònoma de Barcelona, Institut de Ciències Polítiques i Socials.

Carrillo, F. (2001). La quijotada de la séptima papeleta. Revista Cambio, 418, 32-33.

Corte Constitucional. (1991). Constitución Política de Colombia. Gaceta oficial.

Colomer, J. M. (2004). Cómo votamos. Los sistemas electorales del mundo: pasado, presente y futuro. Barcelona, España: Gedisa. 
Chasquetti, D. (2001). Elecciones presidenciales mayoritarias en América Latina. América Latina Hoy, 29, 31-51.

Coppedge, M. (2000). Presidential Run-offs Do Not Fragment Legislative Party Systems. Ponencia presentada en la reunión de la American Political Science Association. Washington D.C.

Crespo, I. (2008). El ballotage en América Lati$n a$, México, Ciudad de México: Universidad Nacional Autónoma de México

Dugas, J. (1993a). La Constitución Política de 1991: ¿un pacto político viable?. En Autor (Coord.), La Constitución de 1991: ¿un pacto político viable? Bogotá: Departamento de Ciencias Políticas, Universidad de los Andes.

Dugas, J. (1993b). El desarrollo de la Asamblea Nacional Constituyente. En Autor (Coord.), La Constitución de 1991: ¿un pacto politico viable? Bogotá, Colombia: Departamento de Ciencias Políticas, Universidad de los Andes.

Duque Daza, J. (2006). Partidos divididos, dirigencia fragmentada: Los partidos Liberal y Conservador colombianos 1974-2006. Convergencia, 13(41), 173-209.

Duque Daza, J. (2008). Redefinición de las reglas de juego: Las lógicas del cambio institucional electoral en Colombia: 1191-2005. En D. Tarapués y G. Sánchez (Coords.), Sistema electoral colombiano: actualidad y perspectivas (pp. 39-74). Santiago de Cali: Poemia.

Duque Daza, J. (2011). Redefinición de las reglas de juego. Las reformas del sistema electoral colombiano como un caso volatilidad institucional 1991-2011, Papel Político, 16(2), 421-460.

Hartlyn, J. (1989). La politica del régimen de coalición. La experiencia del Frente $\mathrm{Na}$ cional en Colombia. Bogotá, Colombia: Tercer Mundo Editores.

Katz, R. (2000). Second ballot (or Runoff). En R. Rose (Ed.), International Encyclo- pedia of Elections. Basingstoke, United Kingdom: Palgrave MacMillan.

Laakso, M., y Taagepera R. (1979). Effective Number of Parties: A Measure with Application to West Europe. Comparative Political Studies, 12, 3-27.

López, C., y Sevillano, Ó. (2008). Balance político de la parapolítica. Recuperado de http://www.ideaspaz.org/tools/download/54297

Martínez, R. (Ed.) (2004). La elección presidencial mediante doble vuelta en América Latina. ICPS, Barcelona.

Martínez, R. (2006). Ventajas y desventajas de la fórmula electoral de doble vuelta, Documentos CIDOB. Serie: América Latina, No. 12. Barcelona, España: CIDOB edicions.

Medina Gallego, C. (1990). Autodefensas, Paramilitaresy Narcotráfico en Colombia: origen, desarrollo y consolidación. El caso de "Puerto Boyacá". Bogotá, Colombia: Documentos Periodísticos.

Molina, V. (2001). Consecuencias políticas del calendario electoral en América Latina: ventajas y desventajas de elecciones simultáneas o separadas para presidente y legislatura. América Latina Hoy, 29, 15-29.

Negretto, G. (2010). La reforma política en América Latina. Reglas electorales y distribución de poder entre Presidente y Congreso. Desarrollo Económico, 50(198), 197-221.

Norris, P. (1997). Choosing Electoral Systems: Proportional, Majoritarian and Mixed System. International Political Science Review, 18(3), 297-312.

Nohlen, D. (1993). Enciclopedia electoral y del Caribe. Instituto Interamericano de Derechos Humanos. San José.

Nohlen, D. (1994). Sistemas electorales y partidos políticos, Ciudad de México, México: Fondo de Cultura Económica. 
Nohlen, D. (1998). El presidencialismo renovado. Caracas, Venezuela: Nueva Sociedad.

Pérez-Liñán, A. (2004). La reversión del resultado y el problema de la gobernabilidad. En R. Martínez (Dir.), La elección presidencial mediante doble vuelta en Latinoamérica (pp. 10-33). Barcelona: ICPS Colección Barcelona.

Pérez-Liñán, A. (2006). Evaluating Presidential Runoff Elections. Electoral Studies, 25(1), 129-146.

Payne, J. M., Zovatto, D., y Díaz, M. (Eds) (2006). La politica importa. Democracia $y$ desarrollo en América Latina. Washington, Estados Unidos: Banco Interamericano de Desarrollo.

Quintero, O. A. (2002). Sociología e historia del movimiento estudiantil por la Asamblea Constituyente de 1991, Revista Colombiana de Sociología, 6(1), 125-151.

Registraduría Nacional del Estado Civil. (2019) Histórico de resultados elecciones presidenciales. Recuperado de https://www. registraduria.gov.co/-Presidencia-.html

Sartori, G. (1994). Ingeniería constitucional comparada: una investigación de estructuras, incentivos y resultados. Ciudad de México, México: Fondo de Cultura Económica.

Semana (abril 17 de 2016). El informe que indica que la parapolítica no es cosa del pasado. Recuperado de https://www.semana.com/ nacion/articulo/procuraduria-adelanta519-investicaciones-por-parapolitica-ybacrimpolitica $/ 470010$

Shugart, M. St., y Carey, J. M. (1992). Presidents and Assemblies: Constitutional Design and Electoral Dynamics. Cambridge: Cambridge University Press.

Shugart, M. (2007). Mayoría relativa vs segunda vuelta. La elección presidencial mexicana de 2006 en perspectiva comparada. Política y Gobierno, 14(1), 175-202.
Verdadabierta.com (julio 27 de 2010). La parapolítica. Recuperado de https://verdadabierta.com/la-para-politica-sp-764685506/

Zamora, G. (1983). Los moradores de la represión en el Magdalena Medio. Bogotá: Centro de Investigación y Educación Popular.

\section{Notas}

1 Ambos se oponen al sistema de Run-offs.

2 El régimen de coalición conocido como Frente Nacional (1958-1974) mantuvo su prolongación parcial hasta la década de los ochenta. Se estableció por parte de las elites de los partidos Liberal y Conservador como una salida a una doble situación que amenazaba su dirigencia política dominante: la violencia partidista que azotaba al país desde la década de los cuarenta y los intentos del dictador Gustavo Rojas Pinilla (1953-1957) de proseguir en el poder mediante la búsqueda de su reelección (Véase Hartlyn, 1989).

3 Obtenido a través la adaptación del Número Efectivo de Partidos (Laakso y Taagepera, 1979), en donde Ci es la proporción de votos de cada candidato:

$$
\begin{aligned}
& \mathrm{NEC}=-1- \\
& \sum \mathrm{Ci}^{2}
\end{aligned}
$$

Esta adaptación permite ponderar el peso de cada candidato descartando aquellos que solo obtienen resultados marginales y que participan sin tener opciones reales, en algunos casos se trata de aventuras políticas sin fundamento.

4 El Índice de Concentración se obtiene sumando los porcentajes de los dos candidatos o partidos con mayor votación.

5 El politólogo francés señalaba que "el escrutinio mayoritario a dos vueltas tiende a crear un sistema de partidos múltiples, flexibles, dependientes y relativamente estables" (Duverger, 1964, p. 232). 
6 "A finales de la década del ochenta, hubo tres intentos de reformas durante el gobierno de Virgilio Barco (1986-1990), pero fracasaron. El primero consistió en una propuesta de un plebiscito para modificar esta norma; la iniciativa no prosperó. Tampoco lo hizo la propuesta del mismo presidente para que se llegara a un acuerdo partidista sobre una reforma que luego sería sometida a un referendo. La tercera propuesta consistió en un proyecto de ley tramitado en el Congreso de la República para convocar a un referendo que logró un cierto consenso, pero el gobierno optó por retirarlo pues, en el Congreso, se incluyó una pregunta adicional referida a la extradición de colombianos al exterior. La reforma, fue archivada (ver Roll, 1999; 2001; Dugas et al., 1991, Duque, 2007 y 2011). Durante este periodo, la única reforma que prosperó fue la propuesta por el Partido Liberal de separación de las elecciones para Congreso de la República y las presidenciales. Se pasó de elecciones concurrentes a no concurrentes desde 1978" (Duque Daza, J., 2008, p. 45).

7 Véanse: Zamora (1983), Medina (1990).

8 Como lo describe John Dugas (1993), la lógica de los acuerdos se impuso en la dinámica de la ANC. De los 449 artículos aprobados en primer debate, 192 (43\%) lo fueron por unanimidad; 176 fueron aprobados con más del $90 \%$ de los votos. El 94\% del total de artículos aprobados recibió más del $80 \%$ de los votos (Duque Daza, 2008, p. 48).

$9 \quad$ El Número Efectivo de Partidos Legislativos se calcula según la fórmula propuesta por Laakso y Taagepera (1979), en donde Ei es la proporción de escaños de cada partido:

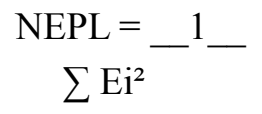

10 La evolución de dos indicadores nos permite visualizar el efecto de incorporación de las reglas electorales de la Constitución de
1991. El primero se refiere al surgimiento de nuevos partidos y movimientos, de 9 partidos inscritos en 1990 ante el Consejo Nacional Electoral se pasó a 22 en 1991, a 54 en 1994, a 80 en 1998 y a 59 en 2002. El segundo indicador se refiere al porcentaje de escaños en el Congreso de la República obtenido por fuerzas políticas diferentes a los partidos Liberal y Conservador. En el Senado pasó del 7,9\% en 1990, al $15 \%$ en $1991,17 \%$ en $1994,16 \%$ en 1998 y $25 \%$ en el 2002. En la Cámara de Representantes pasó del $8 \%$ en 1990 , al $13,8 \%$ en 1991 , $8,7 \%$ en $1994,18,1 \%$ en 1998 y $24,9 \%$ en el 2002. Aunque los partidos Liberal y Conservador continuaron concentrando la mayoría de escaños en el Congreso de la República durante las cuatro elecciones post constituyentes, la presencia de otros partidos en la competencia electoral y con escaños en ambas cámaras fue creciendo, igual sucedió con los Concejos Municipales y las Asambleas Departamentales (Duque, 2007).

11 Véase: Asamblea Nacional Constituyente, Secretaría General, mayo 10 de 1991, Informe a la Plenaria de la Asamblea Nacional Constituyente, p. 2. Recuperado de: http://www.banrepcultural.org/blaavirtual/ ANC/brblaa347296_324.86_L53i.pdf

12 En las elecciones de 1974 la candidata de la Alianza Nacional Popular, ANAPO, María Eugenia Rojas de Moreno Díaz obtuvo el $9,5 \%$ de los votos y Hernando Echeverry Mejía, de la Unión Nacional de Oposición que aglutinó a la izquierda, obtuvo el 2,7\% de los votos. En 1978 el candidato Julio César Pernía, de izquierda, obtuvo el 1,9\% de los votos. En las elecciones de 1982 el candidato de la izquierda, Gerardo Molina alcanzó solo el 1,2\% de la votación. En 1986 participó el candidato de la Unión Patriótica Jaime Pardo Leal, quien en su momento obtuvo la más alta votación de la izquierda con el 4,5\%. En la coyuntura violenta de 1990 el candidato del reinsertado 
movimiento guerrillero M-19 a través del partido Alianza Democrática M-19 obtuvo el $12,5 \%$ de los votos (cifras obtenidas de la Registraduría Nacional del Estado Civil, estadísticas electorales, años respectivos).

13

Se trata de la denominada Parapolítica, proceso con el cual la Corte Suprema de Justicia y la Fiscalía adelantaron investigaciones desde el 2006 a decenas de congresistas por sus nexos con grupos paramilitares. En gran parte del país, dirigentes políticos y algunos funcionarios del Estado se beneficiaron de estos vínculos y mediante la violencia, las amenazas y la intimidación de grupos paramilitares, en algunos casos asociados con personal del Ejército colombiano, asesinaron, desterraron, se apropiaron de tierras, coaccionaron a los electores y se apropiaron de los recursos públicos durante más de una década. Fueron condenados más de 40 congresistas y ex congresistas, lo que hizo que desaparecieran muchos partidos. Desde el 2006 hasta el 2016 se tiene registrado un total de 519 procesos disciplinarios contra funcionarios por vínculos con grupos paramilitares o con bandas criminales. Estos procesos obedecen a conductas homicidio, amenazas, constreñimiento electoral, financiación de campañas políticas, entre otras (Véase: López y Sevillano, 2008).
El Estatuto de la Oposición (Ley 1909 de 2018) establece que el segundo partido en votación en las elecciones presidenciales tiene derecho a una curul en el Senado para el candidato presidencial y una en la Cámara para la fórmula vicepresidencial.

15 El Frente Social y Político fue una agrupación política temporal de izquierda creada en 1999 y conformada por integrada por el Partido Comunista Colombiano, la Unión Patriótica, grupos como Presentes por el Socialismo, Poder y Unidad Popular y organizaciones sociales y sindicales. Participó en las elecciones locales de 2000 y en las de Congreso de 2002. El ex magistrado de la Corte Constitucional y después candidato presidencial por el Polo democrático Alternativo, Carlos Gaviria, fue elegido senador en 2002 por este movimiento. 


\section{Anexo 1}

\section{Colombia Elecciones presidenciales 1994-2014}

\begin{tabular}{|c|c|c|c|c|c|c|}
\hline \multirow[t]{2}{*}{ Año } & \multicolumn{2}{|c|}{ Contendores } & \multicolumn{2}{|c|}{ Primera vuelta } & \multicolumn{2}{|c|}{ Segunda vuelta } \\
\hline & Candidatos & Partidos & Votos & $\%$ & Votos & $\%$ \\
\hline 1974 & $\begin{array}{c}\text {-Alfonso López Michelsen } \\
\text {-Álvaro Gómez Hurtado } \\
\text {-María Eugenia Rojas } \\
\text {-Otros (2 candidatos) } \\
\text { Total }\end{array}$ & $\begin{array}{c}\text { Liberal } \\
\text { Conservador } \\
\text { Anapo } \\
\text { Otros partidos }\end{array}$ & $\begin{array}{r}2.929 .729 \\
1.634 .879 \\
492.162 \\
142.778 \\
5.199 .548 \\
\end{array}$ & $\begin{array}{r}56,3 \\
31,4 \\
9,4 \\
2,9 \\
100\end{array}$ & No había & ----- \\
\hline 1978 & $\begin{array}{c}\text {-Julio César Turbay Ayala } \\
\text {-Belisario Betancur Cuartas } \\
\text {-Otros ( } 3 \text { candidatos) } \\
\text { Total }\end{array}$ & $\begin{array}{c}\text { Liberal } \\
\text { Conservador } \\
\text { Otros }\end{array}$ & $\begin{array}{r}2.503 .681 \\
2.366 .620 \\
187.624 \\
5.057 .925\end{array}$ & $\begin{array}{r}49,5 \\
46,8 \\
3,7 \\
100\end{array}$ & No había & ------ \\
\hline 1982 & $\begin{array}{c}\text {-Belisario Betancur Cuartas } \\
\text {-Alfonso López Michelsen } \\
\text {-Luís Carlos Galán } \\
\text {-Otros ( } 2 \text { candidatos) } \\
\text { Total }\end{array}$ & $\begin{array}{c}\text { Conservador } \\
\text { Liberal } \\
\text { Nuevo Liberalismo } \\
\text { Otros partidos }\end{array}$ & $\begin{array}{r}3.189 .587 \\
2.797 .786 \\
746.024 \\
83.368 \\
6.816 .765 \\
\end{array}$ & $\begin{array}{r}46,8 \\
41,0 \\
10,9 \\
1,3 \\
100,0\end{array}$ & No había & ------ \\
\hline 1986 & $\begin{array}{l}\text {-Virgilio Barco Vargas } \\
\text {-Álvaro Gómez Hurtado } \\
\text {-Jaime Pardo Leal } \\
\text {-Otros (2 candidatos) } \\
\text { Total }\end{array}$ & $\begin{array}{c}\text { Liberal } \\
\text { Conservador } \\
\text { Unión Patriótica } \\
\text { Otros partidos }\end{array}$ & $\begin{array}{r}4.214 .510 \\
2.588 .050 \\
328.752 \\
90.506 \\
7.221 .818 \\
\end{array}$ & $\begin{array}{r}58,3 \\
35,8 \\
4,5 \\
1,4 \\
100,0\end{array}$ & No había & ----- \\
\hline 1990 & $\begin{array}{c}\text {-César Gaviria Trujillo } \\
\text {-Álvaro Gómez Hurtado } \\
\text {-Antonio Navarro Wolf } \\
\text {-Rodrigo Lloreda Caicedo } \\
\text {-Otros (8 candidatos) } \\
\text { Total }\end{array}$ & $\begin{array}{c}\text { Liberal } \\
\text { Mov. de Salvación Nacional } \\
\text { Alianza Democrática M-19 } \\
\text { Conservador } \\
\text { Otros partidos }\end{array}$ & $\begin{array}{r}2.891 .808 \\
1.433 .913 \\
754.740 \\
735.374 \\
108.712 \\
5.924 .547\end{array}$ & $\begin{array}{r}48,8 \\
24,2 \\
12,7 \\
12,4 \\
1,9 \\
100,0\end{array}$ & No había & ----- \\
\hline 1994 & $\begin{array}{c}\text {-Ernesto Samper Pizano } \\
\text {-Andrés Pastrana Arango } \\
\text {-Antonio Navarro Wolf } \\
\text {-Otros (15 candidatos) } \\
\text { Total }\end{array}$ & $\begin{array}{c}\text { Liberal } \\
\text { Conservador } \\
\text { Compromiso Colombia } \\
\text { Otros partidos }\end{array}$ & $\begin{array}{r}2.623 .210 \\
2.604 .771 \\
219.241 \\
278.994 \\
5.726 .216 \\
\end{array}$ & $\begin{array}{r}45,3 \\
45,0 \\
3,8 \\
5,9 \\
100,0\end{array}$ & $\begin{array}{l}3.773 .366 \\
3.576 .781 \\
------ \\
--1.350 .147\end{array}$ & $\begin{array}{r}51,3 \\
49,7 \\
----- \\
---- \\
100,0\end{array}$ \\
\hline 1998 & $\begin{array}{c}\text {-Horacio Serpa } \\
\text {-Andrés Pastrana } \\
\text {-Noemí Sanín } \\
\text {-Harold Bedoya } \\
\text {-Otros (9 candidatos) } \\
\text { Total }\end{array}$ & $\begin{array}{c}\text { Liberal } \\
\text { Conservador } \\
\text { Sí Colombia } \\
\text { Fuerza Colombia } \\
\text { Otros partidos }\end{array}$ & $\begin{array}{r}3.634 .823 \\
3.607 .945 \\
2.824 .735 \\
192.173 \\
247.870 \\
10.507 .546 \\
\end{array}$ & $\begin{array}{r}34,6 \\
34,3 \\
26,9 \\
1,8 \\
2,4 \\
100,0 \\
\end{array}$ & $\begin{array}{r}5.620 .719 \\
6.086 .507 \\
---------- \\
-------- \\
------ \\
11.707 .226 \\
\end{array}$ & $\begin{array}{r}48,0 \\
52,0 \\
----- \\
---- \\
---- \\
100,0\end{array}$ \\
\hline 2002 & $\begin{array}{l}\text {-Álvaro Uribe Vélez } \\
\text {-Horacio Serpa Uribe } \\
\text {-Luís Eduardo Garzón } \\
\text {-Noemí Sanín } \\
\text {-Otros (7 candidatos) } \\
\text { Total }\end{array}$ & $\begin{array}{c}\text { Primero Colombia } \\
\text { Partido Liberal } \\
\text { Frente Social y Político } \\
\text { Sí Colombia } \\
\text { Otros partidos }\end{array}$ & $\begin{array}{r}5.862 .655 \\
3.514 .779 \\
680.245 \\
641.884 \\
155.966 \\
10.855 .529\end{array}$ & $\begin{array}{r}54,0 \\
32,4 \\
6,2 \\
5,9 \\
1,5 \\
100,0\end{array}$ & No hubo & ---- \\
\hline
\end{tabular}




\begin{tabular}{|c|c|c|c|c|c|c|}
\hline \multirow[t]{2}{*}{ Año } & \multicolumn{2}{|c|}{ Contendores } & \multicolumn{2}{|c|}{ Primera vuelta } & \multicolumn{2}{|c|}{ Segunda vuelta } \\
\hline & Candidatos & Partidos & Votos & $\%$ & Votos & $\%$ \\
\hline 2006 & $\begin{array}{c}\text {-Álvaro Uribe Vélez } \\
\text {-Carlos Gaviria Díaz } \\
\text {-Horacio Serpa Uribe } \\
\text {-Antanas Mockus } \\
\text {-Otros (3 candidatos) } \\
\text { Total }\end{array}$ & $\begin{array}{c}\text { Primero Colombia } \\
\text { Polo Democrático Alternativo } \\
\text { Liberal } \\
\text { Alianza Social Indígena } \\
\text { Otros partidos }\end{array}$ & $\begin{array}{r}7.397 .835 \\
2.613 .157 \\
1.404 .275 \\
146.583 \\
76.603 \\
11.638 .453\end{array}$ & $\begin{array}{r}62,3 \\
22,0 \\
11,8 \\
1,2 \\
2,7 \\
100,0\end{array}$ & No hubo & ---- \\
\hline 2010 & $\begin{array}{c}\text {-Juan Manuel Santos } \\
\text {-Antanas Mockus } \\
\text {-Germán Vargas Lleras } \\
\text {-Gustavo Petro } \\
\text {-Noemí Sanín } \\
\text {-Rafael Pardo } \\
\text {-Otros (3 candidatos) } \\
\text { Total }\end{array}$ & $\begin{array}{c}\text { Partido Social de Unidad Nacional } \\
\text { Partido Verde } \\
\text { Cambio Radical } \\
\text { Polo Democrático Alternativo } \\
\text { Partido Conservador } \\
\text { Partido Liberal } \\
\text { Otros partidos }\end{array}$ & $\begin{array}{r}6.758 .539 \\
3.120 .716 \\
1.471 .377 \\
1.329 .512 \\
892.323 \\
636.624 \\
81.705 \\
14.290 .796\end{array}$ & $\begin{array}{r}46,5 \\
21,5 \\
10,1 \\
9,1 \\
6,1 \\
4,4 \\
2,3 \\
100,0\end{array}$ & 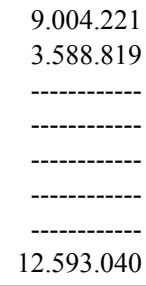 & $\begin{array}{r}71,5 \\
29,5 \\
---- \\
---- \\
---- \\
---- \\
---- \\
100,0\end{array}$ \\
\hline 2014 & $\begin{array}{l}\text {-Juan Manuel Santos } \\
\text {-Óscar Iván Zuluaga } \\
\text {-Marta Lucía Ramírez } \\
\text {-Clara López Obregón } \\
\text {-Enrique Peñalosa } \\
\text { Total }\end{array}$ & $\begin{array}{c}\text { Unidad Nacional } \\
\text { Centro Democrático } \\
\text { Partido Conservador } \\
\text { Polo Democrático Alternativo } \\
\text { Alianza Verde }\end{array}$ & $\begin{array}{r}3.310 .794 \\
3.769 .005 \\
1.997 .980 \\
1.958 .518 \\
1.064 .758 \\
12.101 .055\end{array}$ & $\begin{array}{r}25,7 \\
29,3 \\
15,5 \\
15,2 \\
8,3 \\
100,0\end{array}$ & $\begin{array}{r}\text { 7.839.342 } \\
\text { 6.917.001 } \\
--------- \\
------ \\
-------- \\
14.756 .343\end{array}$ & $\begin{array}{r}51,0 \\
49,0 \\
---- \\
---- \\
---- \\
100,0\end{array}$ \\
\hline 2018 & $\begin{array}{l}\text {-Iván Duque Márquez } \\
\text {-Gustavo Petro } \\
\text {-Sergio Fajardo } \\
\text {-Germán Vargas Lleras } \\
\text {-Humberto de la Calle } \\
\text {-Jorge Antonio Trujillo } \\
\text {-Viviane Morales }\end{array}$ & $\begin{array}{c}\text { Centro Democrático } \\
\text { Coalición Colombia Humana } \\
\text { Compromiso Ciudadano } \\
\text { Coal. Mejor Vargas Ll.-Cambio Radical } \\
\text { Liberal } \\
\text { Todos Somos Colombia } \\
\text { Somos Región Colombia }\end{array}$ & $\begin{array}{r}7.569 .693 \\
4.851 .254 \\
4.589 .696 \\
1.407 .840 \\
399.180 \\
75.614 \\
41.458\end{array}$ & $\begin{array}{r}39,1 \\
25,1 \\
23,7 \\
7,3 \\
2,1 \\
0,4 \\
0,2\end{array}$ & 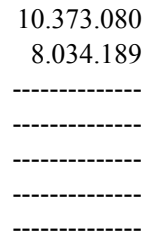 & $\begin{array}{l}54,0 \\
41,8\end{array}$ \\
\hline
\end{tabular}

Fuente: elaboración del autor con estadísticas de la Registraduría Nacional del Estado Civil. 